\title{
A Diagnosis of the Seasonally and Longitudinally Varying Midlatitude Circulation Response to Global Warming*
}

\author{
ISLA R. Simpson, TIFFANy A. SHAW, AND RichaRd SEAGER \\ Lamont-Doherty Earth Observatory, Columbia University, New York, New York
}

(Manuscript received 11 October 2013, in final form 9 February 2014)

\begin{abstract}
Zonal-mean or basin-mean analyses often conclude that the midlatitude circulation will undergo a poleward shift with global warming. In this study, the models from phase 5 of the Coupled Model Intercomparison Project are used to provide a detailed examination of midlatitude circulation change as a function of longitude and season. The two-dimensional vertically integrated momentum budget is used to identify the dominant terms that maintain the anomalous surface wind stress, thereby allowing a distinction between features that are maintained by high-frequency eddies and those that involve changes in the lowerfrequency or stationary flow.

In the zonal mean, in each season and hemisphere there is a poleward shifting of the midlatitude surface wind stress, primarily maintained by high-frequency transient eddies. This is not necessarily the case locally. In the Southern Hemisphere, for the most part, the interpretation of the response as being a high-frequency eddy-driven poleward shifting of the midlatitude westerlies holds true. The Northern Hemisphere is considerably more complex with only the fall months showing a robust poleward shift of both the Atlantic and Pacific jets. During the winter months the jet in the east Pacific actually shifts equatorward and the Atlantic jet strengthens over Europe. An important role for altered climatological stationary waves in these responses is found. This motivates future work that should focus on zonal asymmetries and stationary wave changes, as well as the changes in high-frequency transients that bring about the poleward shifting of the westerlies in the zonal mean.
\end{abstract}

\section{Introduction}

The midlatitudes are dominated by westerly jet streams and storm tracks that govern the geographical distribution of precipitation and temperature and their variability. On their equatorward side lie the vast subtropical dry zones and the monsoons. Rising greenhouse gases are expected to both intensify these climate contrasts and shift the border between them (Held and Soden 2006; Solomon et al. 2007; Seager et al. 2010). As part of an effort to comprehend these changes there is therefore a great deal of research underway to predict, using global climate models (GCMs),

\footnotetext{
* Lamont-Doherty Earth Observatory Contribution Number 7780 .
}

Corresponding author address: Isla Simpson, Division of Ocean and Climate Physics, Lamont-Doherty Earth Observatory, P.O. Box 1000, Route 9W, Palisades, NY 10964-1000.

E-mail: isla@ldeo.columbia.edu how the midlatitude circulation and associated storm tracks and hydroclimate will change in the future and how this will impact regional climates.

Through the use of multimodel ensembles, a consensus has emerged that the midlatitude circulation will undergo a poleward shift in response to anthropogenic greenhouse gas emissions. This has been determined using various metrics including 1) simple metrics of the climatological zonal-mean or basin-mean jet location (e.g., Fyfe and Saenko 2006; Kidston and Gerber 2010; Swart and Fyfe 2012; Wilcox et al. 2012; Woollings and Blackburn 2012; Barnes and Polvani 2013; Bracegirdle et al.2013),2) methods based on the projection of zonal wind or sea level pressure anomalies onto the dominant modes of variability (e.g., the northern or southern annular modes) (e.g., Miller et al. 2006; Previdi and Liepert 2007; Woollings and Blackburn 2012; Gillett and Fyfe 2013), or 3) trends in diagnostics related to storm-track activity (e.g., Yin 2005; Chang et al. 2012). That being said, this consensus is not without dispute, particularly in the Northern Hemisphere (NH). For 
example, Morgenstern et al. (2010) found a negative signal in the wintertime North Atlantic Oscillation (NAO) in association with $\mathrm{CO}_{2}$ emissions in coupled chemistry-climate models that have a good representation of stratospheric processes. A poleward shift is also somewhat unclear in NH near-surface storm-track measures using some metrics (Catto et al. 2011; Harvey et al. 2012).

Research into the understanding of midlatitude circulation change has primarily focused on the mechanisms by which the zonal-mean poleward shifting of the midlatitude westerlies is produced. This most likely occurs through the effect of the more direct thermal perturbations associated with increasing greenhouse gases on the propagation, growth, or dissipation of transient eddies (Butler et al. 2010; Lorenz and DeWeaver 2007). However, the exact mechanism(s) by which the midlatitude transients are influenced remains under debate, with studies advocating for the importance of 1) changes in subtropical static stability affecting the growth of baroclinic eddies ( $\mathrm{Lu}$ et al. 2008), 2) altered lower-tropospheric midlatitude static stability changing the eddy length scale (Kidston et al. 2010, 2011), 3 ) changes in upper-tropospheric-lower-stratospheric thermal and zonal wind structures altering the propagation or refraction of synoptic scale eddies (Simpson et al. 2009; Wu et al. 2013; Chen et al. 2013), 4) the acceleration of upper-tropospheric-lower-stratospheric westerlies changing the eddy phase speed (Chen et al. 2008; Lu et al. 2008), and 5) altered upper-level baroclinicity changing the dominant eddy length scale (Riviere 2011). Wu et al. (2012, 2013) considered many of these mechanisms and found that an explanation in terms of a tropospheric adjustment, via linear wave refraction, to stratospheric wind changes, has the best explanatory power.

The majority of the above studies have drawn conclusions based upon the zonal-mean circulation response and have often made use of simplified GCMs with zonally symmetric boundary conditions where high-frequency transients dominate the response. Zonal variations in the midlatitude circulation response have received much less attention in the literature but are certainly of great importance for understanding regional climate change since, locally, very few places experience the zonal mean, particularly in the NH.

While the midlatitude westerlies in the storm-track regions are primarily maintained by high-frequency transient eddy momentum fluxes, locally there can be a substantial influence from lower-frequency and stationary wave motions. This is most apparent in the $\mathrm{NH}$ climatological circulation where orography, land-sea temperature contrasts, and sea surface temperature patterns result in the dominance of large scale planetary waves (Held et al. 2002) that break up the midlatitude circulation into localized storm tracks (Brayshaw et al. 2009, 2011). Aside from these climatological zonal asymmetries, low-frequency motions generated by, for example, Rossby wave forcing from the tropics (Hoskins and Karoly 1981), changing zonal flow over topography or low-frequency atmospheric variability driven by the higher-frequency transients are also important.

It is well known that the character of extratropical atmospheric motions on time scales less than about 10 days is quite distinct from those of lower-frequency motions (Hoskins et al. 1983; Wallace and Blackmon 1983; Blackmon et al. 1984), reflecting the fact that they are generated by these different mechanisms. The highfrequency motions bear the signatures of baroclinic instability. They are predominantly of synoptic scale, meridionally elongated (Hoskins et al. 1983), and result in geopotential height variance that is localized over the baroclinic storm-track regions (Wallace and Blackmon 1983). The lower-frequency motions tend to be of larger scale, zonally elongated (Hoskins et al. 1983), with an equivalent barotropic structure and very little horizontal phase propagation (Blackmon et al. 1984), and they result in geopotential height variance in quite distinct locations (Wallace and Blackmon 1983).

Given this distinction between the behavior of the high-frequency transients and the lower-frequency motions and climatological stationary flow, we are motivated to separate out the relative importance of these different types of motion for future midlatitude circulation change. In practice, making this distinction is not straightforward because the high-frequency transients and lower-frequency and stationary flow are highly coupled, making it difficult to unambiguously attribute causality of localized mean flow anomalies to one or the other. Nevertheless, diagnosing where the high-frequency transients dominate and where lower-frequency and/or stationary motions are important is a useful step toward understanding mechanisms relevant for regional climate change. It allows us to determine where the mechanisms based on a change in the high-frequency transients are the complete story and where we must go beyond this and understand why stationary or low-frequency waves change.

While some studies have had a more regional focus (Stephenson and Held 1993; Lorenz and DeWeaver 2007; Woollings and Blackburn 2012; Neelin et al. 2013), a complete assessment of the zonal asymmetries in the midlatitude response to climate change and the relative importance of high-frequency transients and the lowerfrequency or stationary flow in maintaining them has 
not, to our knowledge, been performed. This motivates the current assessment of the future predictions for the midlatitude circulation by phase 5 of the Coupled Model Intercomparison Project (CMIP5) models, with a particular focus on zonal asymmetries. Using the unprecedented number of models with sufficient time and spatial resolution, we perform a multimodel assessment of the momentum budget of future changes in the midlatitude circulation. While we cannot hope to unambiguously establish causality in quasi-equilibrium situations with comprehensive GCMs, we can at least document the terms that maintain the near-surface zonal wind changes and, in particular, the relative importance of the high-frequency transients as compared to the lower-frequency and stationary flow. This can then be used as motivation for further idealized experiments that can attempt to establish causality and disentangle the mechanisms by which the highly coupled high-frequency transients and lower-frequency and stationary flow are altered.

We begin with a description of the model data and the method used to close the two-dimensional vertically integrated momentum budget in section 2 . The historical momentum budget is first examined in section 3 and this is followed by an analysis of the zonal-mean response to global warming in section 4 . The model predictions for this response as a function of season and longitude are then discussed in section 5 and the vertically integrated momentum budget for these changes is analyzed in section 6 , before discussion and conclusions are provided in sections 7 and 8 . In the appendix we provide a brief comparison of the CMIP5 momentum budget with that for the Interim European Centre for Medium-Range Weather Forecasts (ECMWF) ReAnalysis (ERA-Interim).

\section{Model data and diagnostics}

\section{a. The model experiments}

Data from CMIP5 are used. The years 1979-2005 of the historical simulation are considered the "past" and years 2070-2099 of the representative concentration pathway 8.5 (RCP8.5) scenario simulation are considered the "future." We begin by assessing future changes in the midlatitude zonal wind and their robustness using the maximum number of models available. Both monthly mean and daily zonal wind $(u)$ data are used for the models and ensemble members listed in Table 1.

The momentum budget of these changes is then evaluated for one member (typically $r 1 i 1 p 1$ ) of a smaller 13-model subset, highlighted in boldface in Table 1 . These are all the models for which the necessary data were available for both scenarios at the time of writing and for which the momentum budget could be successfully closed. ${ }^{1}$ It is shown that, for the most part, they exhibit similar behavior to the multimodel mean of the larger ensemble. This calculation makes use of the 6-hourly hybrid sigma level zonal and meridional $(v)$ winds as well as monthly mean surface pressure $\left(p_{s}\right)$, geopotential $(\Phi)$ and westerly surface wind stress $\left(\tau_{u}\right)$, daily nearsurface wind fields $\left(u_{s}\right.$ and $\left.v_{s}\right)$, specific humidity $\left(q_{s}\right)$ and temperature $\left(T_{s}\right)$, and the surface geopotential $\left(\Phi_{s}\right)$. The 6-hourly data are necessary for accurate evaluation of momentum fluxes, particularly in the Southern Hemisphere ( $\mathrm{SH})$, and the hybrid level data were used because 6-hourly pressure level data were only available on three vertical levels. The hybrid $u$ and $v$ are first interpolated onto the pressure levels for which the $\Phi$ output is available (i.e., $1000,925,850,700,600,500,400$, $300,250,200,150,100,70,50,30,20$, and $10 \mathrm{hPa}$ ) using a log-pressure interpolation. These are the 17 levels used for the following vertically integrated momentum budget. Only the levels that are above the monthly mean surface pressure are used in the vertical integration and during instances where these levels are below the surface over the course of a month, data are extrapolated below the ground by using those of the lowest model level.

\section{b. The momentum budget calculation}

To diagnose the contributions to the maintenance of the anomalous zonal wind, the zonal momentum budget is analyzed. This was considered preferable to the vorticity budget as it can be directly related to zonal wind changes discussed in previous studies and is easier to close with the model data since it does not involve the higher-order derivatives present in the vorticity budget. Several choices are made to optimize for the closing of the budget with the available data. It is calculated on pressure levels since geopotential output was not provided directly on model hybrid sigma levels. On pressure levels, the zonal momentum budget can be written

\footnotetext{
${ }^{1}$ The momentum budget could not be closed for ACCESS1.0, ACCESS1.3, and HadGEM2-ES since the necessary data for interpolation from hybrid height coordinates to pressure levels were not provided. For reasons unknown, it was not possible to interpolate GISS-E2-R and GISS-E2-H onto pressure levels in a manner that was consistent with the geopotential height output available in the archive and also for reasons unknown it was also not possible to close the momentum budget for CNRM-CM5, IPSL-CM5A-LR, and FGOALS-g2. The geopotential height data for CSIRO Mk3.6.0 contained severe Gibbs fringes effects so the budget could not be closed.
} 
TABLE 1. List of historical and RCP8.5 simulations with the required fields. The models highlighted in boldface are those used in the momentum budget diagnosis.

\begin{tabular}{|c|c|c|c|c|c|}
\hline \multirow[b]{2}{*}{ Model } & \multirow[b]{2}{*}{ Expansion } & \multicolumn{2}{|c|}{$\begin{array}{c}\text { Historical } \\
\text { members }\end{array}$} & \multicolumn{2}{|c|}{$\underline{\text { RCP8.5 members }}$} \\
\hline & & Monthly & Daily & Monthly & Daily \\
\hline ACCESS1.0 & $\begin{array}{l}\text { Australian Community Climate and Earth-System Simulator, } \\
\text { version } 1.0\end{array}$ & 1 & 1 & 1 & 1 \\
\hline ACCESS1.3 & $\begin{array}{l}\text { Australian Community Climate and Earth-System Simulator, } \\
\text { version } 1.3\end{array}$ & 1 & 1 & 1 & 1 \\
\hline BCC_CSM1.1 & Beijing Climate Center, Climate System Model, version 1.1 & 3 & 1 & 1 & 1 \\
\hline BCC_CSM1.1-m & $\begin{array}{l}\text { Beijing Climate Center, Climate System Model, version 1.1, } \\
\text { moderate resolution }\end{array}$ & 3 & 1 & 1 & 1 \\
\hline BNU-ESM & Beijing Normal University - Earth System Model & 1 & 1 & 1 & 1 \\
\hline CanESM2 & Second Generation Canadian Earth System Model & 5 & 5 & 5 & 5 \\
\hline CCSM4 & Community Climate System Model, version 4 & 6 & 1 & 6 & 1 \\
\hline CESM1 (CAM5) & $\begin{array}{l}\text { Community Earth System Model, version } 1 \text { (Community } \\
\text { Atmosphere Model, version 5) }\end{array}$ & 3 & - & 1 & - \\
\hline CESM1 (WACCM) & $\begin{array}{l}\text { Community Earth System Model, version } 1 \text { (Whole Atmosphere } \\
\text { Community Climate Model) }\end{array}$ & 1 & - & 1 & - \\
\hline CMCC-CM & Centro Euro-Mediterraneo sui Cambiamenti Climatici Climate Model & 1 & 1 & 1 & 1 \\
\hline CMCC-CMS & $\begin{array}{l}\text { Centro Euro-Mediterraneo sui Cambiamenti Climatici Climate } \\
\text { Model with a resolved stratosphere }\end{array}$ & 1 & - & 1 & - \\
\hline CNRM-CM5 & $\begin{array}{l}\text { Centre National de Recherches Météorologiques Coupled Global } \\
\text { Climate Model, version } 5\end{array}$ & 10 & 1 & 5 & 1 \\
\hline CSIRO Mk3.6.0 & $\begin{array}{l}\text { Commonwealth Scientific and Industrial Research Organisation } \\
\text { Mark 3.6.0 }\end{array}$ & 10 & 1 & 10 & 1 \\
\hline FGOALS-g2 & $\begin{array}{l}\text { Flexible Global Ocean-Atmosphere-Land System Model gridpoint, } \\
\text { version } 1.0\end{array}$ & 5 & 2 & 1 & 1 \\
\hline FIO-ESM & First Institute of Oceanography (FIO) Earth System Model (ESM) & 3 & - & 3 & - \\
\hline GFDL CM3 & Geophysical Fluid Dynamics Laboratory Climate Model, version 3 & 5 & 5 & 1 & 1 \\
\hline GFDL-ESM2G & $\begin{array}{l}\text { Geophysical Fluid Dynamics Laboratory Earth System Model with } \\
\text { Generalized Ocean Layer Dynamics (GOLD) component }\end{array}$ & 1 & 1 & 1 & 1 \\
\hline GFDL-ESM2M & $\begin{array}{l}\text { Geophysical Fluid Dynamics Laboratory Earth System Model with } \\
\text { Modular Ocean Model } 4 \text { (MOM4) component (ESM2M) }\end{array}$ & 1 & 1 & 1 & 1 \\
\hline GISS-E2H & $\begin{array}{l}\text { Goddard Institute for Space Studies Model E, coupled with the } \\
\text { HYCOM ocean model }\end{array}$ & 5 & - & 1 & - \\
\hline GISS-E2-R & $\begin{array}{l}\text { Goddard Institute for Space Studies Model E, coupled with the } \\
\text { Russell ocean model }\end{array}$ & 5 & - & 1 & - \\
\hline HadGEM2-AO & $\begin{array}{l}\text { Hadley Centre Global Environment Model, version } 2 \text { - Atmosphere } \\
\text { and Ocean }\end{array}$ & 1 & - & 1 & - \\
\hline HadGEM2-CC & Hadley Centre Global Environment Model, version 2 - Carbon Cycle & 2 & 1 & 1 & 1 \\
\hline HadGEM2-ES & Hadley Centre Global Environment Model, version 2 - Earth System & 3 & - & 3 & - \\
\hline INM-CM4.0 & Institute of Numerical Mathematics Coupled Model, version 4.0 & 1 & 1 & 1 & 1 \\
\hline IPSL-CM5A-LR & $\begin{array}{l}\text { L'Institut Pierre-Simon Laplace Coupled Model, version 5, coupled } \\
\text { with NEMO, low resolution }\end{array}$ & 5 & 5 & 4 & 1 \\
\hline IPSL-CM5A-MR & $\begin{array}{l}\text { L'Institut Pierre-Simon Laplace Coupled Model, version 5, coupled } \\
\text { with NEMO, mid resolution }\end{array}$ & 1 & 1 & 1 & 1 \\
\hline IPSL-CM5B-LR & $\begin{array}{l}\text { L'Institut Pierre-Simon Laplace Coupled Model, version 5, coupled } \\
\text { with NEMO, low resolution }\end{array}$ & 1 & - & 1 & - \\
\hline MIROC5 & Model for Interdisciplinary Research on Climate, version 5 & 4 & 4 & 3 & 3 \\
\hline MIROC-ESM & $\begin{array}{l}\text { Model for Interdisciplinary Research on Climate, Earth System } \\
\text { Model }\end{array}$ & 3 & 3 & 1 & 1 \\
\hline MIROC-ESM-CHEM & $\begin{array}{l}\text { Model for Interdisciplinary Research on Climate, Earth System } \\
\text { Model, Chemistry Coupled }\end{array}$ & 1 & 1 & 1 & 1 \\
\hline MPI-ESM-LR & Max Planck Institute Earth System Model, low resolution & 3 & 3 & 3 & 3 \\
\hline MPI-ESM-MR & Max Planck Institute Earth System Model, medium resolution & 3 & 3 & 1 & 1 \\
\hline MRI-CGCM3 & $\begin{array}{l}\text { Meteorological Research Institute Coupled Atmosphere-Ocean } \\
\text { General Circulation Model, version } 3\end{array}$ & 3 & 1 & 1 & 1 \\
\hline NorESM1-M & Norwegian Earth System Model, version 1 (intermediate resolution) & 3 & 3 & 1 & 1 \\
\hline NorESM1-ME & $\begin{array}{l}\text { Norwegian Earth System Model, version } 1 \text { (intermediate resolution), } \\
\text { with prognostic biogeochemical cycling }\end{array}$ & 1 & - & 1 & - \\
\hline
\end{tabular}




$$
\begin{aligned}
\frac{\partial u}{\partial t}= & f v-\frac{1}{a \cos \phi} \frac{\partial \Phi}{\partial \lambda}-\frac{1}{a \cos ^{2} \phi} \frac{\partial\left(u v \cos ^{2} \phi\right)}{\partial \phi} \\
& -\frac{1}{a \cos \phi} \frac{\partial(u u)}{\partial \lambda}-\frac{\partial(u \omega)}{\partial p}+F_{u}+X,
\end{aligned}
$$

where $a$ is Earth's radius, $\lambda$ is longitude, $\phi$ is latitude, $\omega$ is vertical (pressure) velocity, $f$ is the Coriolis parameter, $F_{u}$ is the zonal wind tendency due to friction, and $X$ represents the zonal wind tendency associated with all other parameterized processes, such as diffusion and gravity wave drag.

The monthly mean of each of these terms, denoted $\overline{(\cdot)}$, is evaluated and then the mass-weighted vertical integral from zero to $p_{s}$, denoted $|\cdot|$, is evaluated according to

$$
\overline{|\cdot|}=\frac{1}{g} \int_{0}^{p_{s}(\lambda, \phi, t)} \overline{(\cdot)} d p
$$

where $g$ is the acceleration due to gravity. Upon vertical integration the term involving $\omega$ reduces to a single surface term $\overline{u_{s} \omega_{s}}$. The surface vertical velocity $\omega_{s}$ is calculated using

$$
\bar{\omega}_{s}=\frac{d p_{s}}{d t}=\frac{\partial p_{s}}{\partial t}+\frac{u_{s}}{a \cos \phi} \frac{\partial p_{s}}{\partial \lambda}+\frac{v_{s}}{a} \frac{\partial p_{s}}{\partial \phi} .
$$

This term is extremely small and, while included in the overall budget summation, will not be discussed. Furthermore, the vertical integration of the zonal wind tendency due to friction in this manner yields $-\tau_{u}$, where $\tau_{u}$ is the westerly surface wind stress, a field that is available for each model.

If the small, monthly mean accelerations associated with the seasonal cycle $\overline{\partial u / \partial t}$ are neglected then we are left with the following steady state, vertically integrated momentum budget

$$
f|\bar{v}|-\left|\Phi_{\lambda}\right|-\left|(\overline{u v})_{\phi}\right|-\left|(\overline{u u})_{\lambda}\right|-\overline{u_{s} \omega_{s}}+\bar{X}=\bar{\tau}_{u},
$$

where subscripts $\lambda$ and $\phi$ denote the longitudinal and latitudinal derivatives in (1). The difference between $|f \bar{v}|$ and $\left|\bar{\Phi}_{\lambda}\right|$ is the Coriolis force on the vertically integrated ageostrophic meridional wind $\left(\bar{v}_{a}\right)$; that is,

$$
f\left|\bar{v}_{a}\right|-\left|(\overline{u v})_{\phi}\right|-\left|(\overline{u u})_{\lambda}\right|-\overline{u_{s} \omega_{s}}+\bar{X}=\bar{\tau}_{u} .
$$

The forcing terms (left) maintain the westerly surface wind stress (right).

The zonal and meridional momentum fluxes are further decomposed as follows. The zonal and meridional winds are first decomposed into a zonal-mean component $[\cdot]$ and an eddy component $(\cdot)^{*}$. The eddy component is then decomposed into different frequency bands. Highfrequency motions, $(\cdot)_{H}$, are extracted from the 6-hourly data using a 10-day high-pass Lanczos filter with 181 weights (Duchon 1979). The remaining low-frequency component is further decomposed into a "quasi stationary" component $(\cdot)_{S}$, using a 40-day low-pass Lanczos filter with 181 weights, and the remaining 10-40-day bandpass-filtered contribution, referred to as "low frequency" $(\cdot)_{L}$. To accommodate the time filtering, the first and last years of each period are omitted from the momentum budget analysis. The momentum fluxes of these different frequency bands are calculated using the 6-hourly data (after filtering) before taking the monthly average.

The result is that the fluxes are decomposed into a large number of components. These can be grouped together into high-frequency, low-frequency, quasi-stationary, and cross-frequency contributions such that (5) can be rewritten as

$$
\begin{gathered}
-\left|\overline{[u][v]}_{\phi}\right|-\left|{\overline{\left(u_{H}^{*} v_{H}^{*}\right)_{\phi}}}_{\phi}-\right| \overline{\left(u_{H}^{*} u_{H}^{*}\right)_{\lambda}} \mid+ \text { STAT } \\
+ \text { LOW + CROSS }-{\overline{u_{s} \omega_{s}}}+\bar{X}=\bar{\tau}_{u},
\end{gathered}
$$

where

$$
\begin{aligned}
& \operatorname{STAT}=f\left|\bar{v}_{a}\right|-\left|\overline{\left(u_{S}^{*} v_{S}^{*}\right)_{\phi}}\right|-\left|\overline{\left(u_{S}^{*} u_{S}^{*}\right)_{\lambda}}\right|-2\left|\overline{\left(u_{S}^{*}[u]\right)_{\lambda}}\right|
\end{aligned}
$$

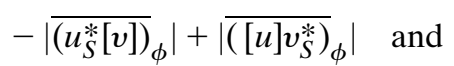

$$
\begin{aligned}
& \mathrm{LOW}=-\left|\overline{\left(u_{L}^{*} v_{L}^{*}\right)_{\phi}}\right|-\left|\overline{\left(u_{L}^{*} u_{L}^{*}\right)_{\lambda}}\right|-2\left|\overline{\left(u_{L}^{*}[u]\right)_{\lambda}}\right| \\
& -\left|{\overline{\left(u_{L}^{*}[v]\right)_{\phi}}}_{\phi}-\right|{\overline{\left([u] v_{L}^{*}\right)_{\phi}}} \text {; }
\end{aligned}
$$

that is, STAT contains all terms that involve pure quasistationary eddy terms or the interaction between the quasi-stationary eddies and the zonal-mean flow $\left(\left|v_{a}\right|\right.$ is dominated by the quasi-stationary eddy component). LOW is similar but for the low-frequency contributions and the remaining CROSS term contains all crossfrequency terms as well as the terms involving the interaction of the high-frequency eddies with the zonal mean. This CROSS contribution is relatively small and, for the most part, will not be shown explicitly. The STAT and LOW frequency components will be left combined as in (7) and (8) for simplicity. The highfrequency fluxes are left separate throughout the analysis as it will be shown that $-\left|\overline{\left(u_{H}^{*} u_{H}^{*}\right)_{\phi}}\right|$ dominates in the zonal-mean response and it is therefore useful to determine the longitudinal distribution of this term on its own, whereas the $-\left|\overline{\left(u_{H}^{*} u_{H}^{*}\right)_{\lambda}}\right|$ contribution is relatively unimportant. Note that the conclusions as to the relative 
importance of the high-frequency transients hold if, instead, it is inferred using the various transforms that exist in the literature that take into account the contributions of the transient eddies through their influence in the meridional momentum equation and resulting Coriolis acceleration (Hoskins et al. 1983; Plumb 1986). In many instances we begin by presenting the budget from the perspective of determining what is the role of the highfrequency transients as compared to the rest (i.e., STAT, LOW, and CROSS combined), before providing a further decomposition into the important components.

The choice of a 10-day threshold in the definition of high-frequency transients is motivated by the observations, outlined in the introduction, that there is a fundamentally different character of motions on either side of this cutoff (Hoskins et al. 1983). The quasi-stationary component can be considered as representing changes to the climatological stationary waves whereas the low-frequency component will include features such as slowly varying large-scale Rossby waves, blocking events, etc. Although, it should be noted that the LOW and STAT need not necessarily reflect different physical processes. For example, low-frequency Rossby waves generated from a quasi-stationary location in space will also show up in the climatological stationary contribution.

The use of monthly $\Phi$ means that the vertical integration (2) has to be performed on the monthly mean values with the monthly mean surface pressure at the lower bound of the integral. This approximation is considered preferable to using daily values of geopotential which are only available on eight levels. The trapezoidal rule is used for the vertical integration. For a field $x$ defined on pressure levels, the contribution to (2) from the interior layers of the atmosphere are evaluated by

$$
\sum_{k=1}^{K-1} \frac{x_{k}+x_{k+1}}{2}\left(p_{k}-p_{k+1}\right)
$$

where the level $k=1$ denotes the lowest pressure level above the surface pressure and the level $k=K$ is the highest pressure level available. The contribution from the top level is given by $\left(x_{k} / 2\right) p_{k}$. At the lower boundary $p_{s}$, the daily near-surface zonal and meridional wind fields are used where available. For models that do not have these fields available, the zonal and meridional winds on the lowest hybrid sigma level are used. Care must be taken at the surface to account for the fact that gradients are not being evaluated on a constant pressure level. The zonal gradient on $p_{s}$ can be transformed into the zonal gradient on a constant pressure surface that intersects $p_{s}$ at a given longitude by

$$
\left.\frac{\partial(\cdot)}{\partial \lambda}\right|_{p}=\left.\frac{\partial(\cdot)}{\partial \lambda}\right|_{p_{s}}-\frac{\partial(\cdot)}{\partial p}\left(\frac{\partial p_{s}}{\partial \lambda}\right) .
$$

For the $\Phi$ gradient at the lower boundary, (10) becomes

$$
\left.\frac{\partial \Phi}{\partial \lambda}\right|_{p}=\left.\frac{\partial \Phi}{\partial \lambda}\right|_{p_{s}}+\frac{R T_{s}}{p_{s}} \frac{\partial p_{s}}{\partial \lambda},
$$

where $R$ is the gas constant, which for a moist atmosphere is given by $R=(1+0.61 q) R_{d}, q$ is the specific humidity, and $R_{d}$ is the dry gas constant $\left(287.06 \mathrm{~J} \mathrm{~kg}^{-1} \mathrm{~K}^{-1}\right)$. The surface values $T_{s}$ and $q_{s}$ are used in the evaluation of (11). The contribution to the vertical integral from the lowest level for the geopotential gradient term is therefore given by

$$
\frac{\left.\frac{\partial \Phi}{\partial \lambda}\right|_{p_{s}}+\left.\frac{\partial \Phi}{\partial \lambda}\right|_{p_{1}}}{2}\left(p_{s}-p_{1}\right)+\frac{\frac{R T_{s}}{p_{s}} \frac{\partial p_{s}}{\partial \lambda}}{2}\left(p_{s}-p_{1}\right) .
$$

All zonal and meridional gradients are calculated using a centered finite difference except at intersections with topography where a one-sided difference is used. For plotting purposes the vertically integrated terms are isotropically smoothed in the spectral domain according to Sardeshmukh and Hoskins [1984, their Eq. (9), with coefficients $n_{0}=21$ and $\left.r=1\right]$.

This is considered to be the optimum method for obtaining a reasonable estimate of the momentum budget, but there are various approximations that render the calculation imperfect and so we must expect some residuals, particularly around steep topography. These approximations include, in no particular order of importance,

- with the exception of surface friction, the tendencies due to other parameterized processes $(X)$ (e.g., orographic gravity wave drag and diffusion) are not available;

- the evaluation of zonal and meridional gradients in a manner that is inconsistent with model numerics;

- the use of a limited vertical resolution for evaluation of the vertical integral; and

- the use of monthly mean $p_{s}$, as opposed to higher time resolution, at the lower boundary of the integration.

Nevertheless, the effect of these approximations is small enough that the budget closes sufficiently well, for the models used, that reasonable conclusions can be drawn from it.

\section{The historical vertically integrated momentum budget}

Before examining future changes in the midlatitude circulation it is instructive to examine the climatological 
(a) Historical Budget

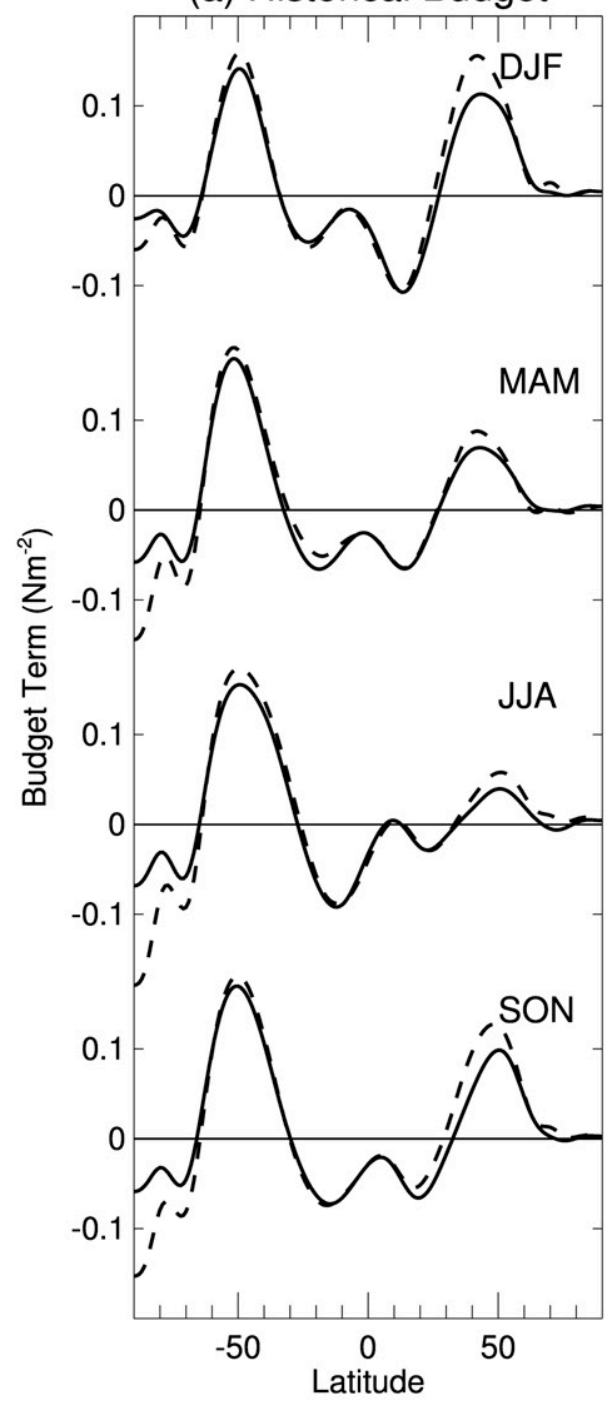

- $\tau_{u}$ - - - Sum (b) Budget decomposition
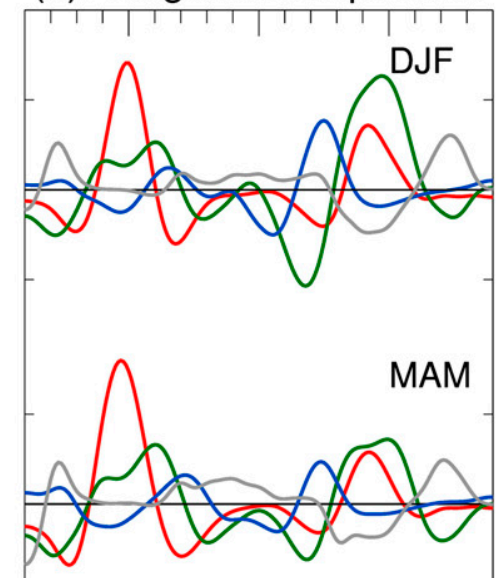

.

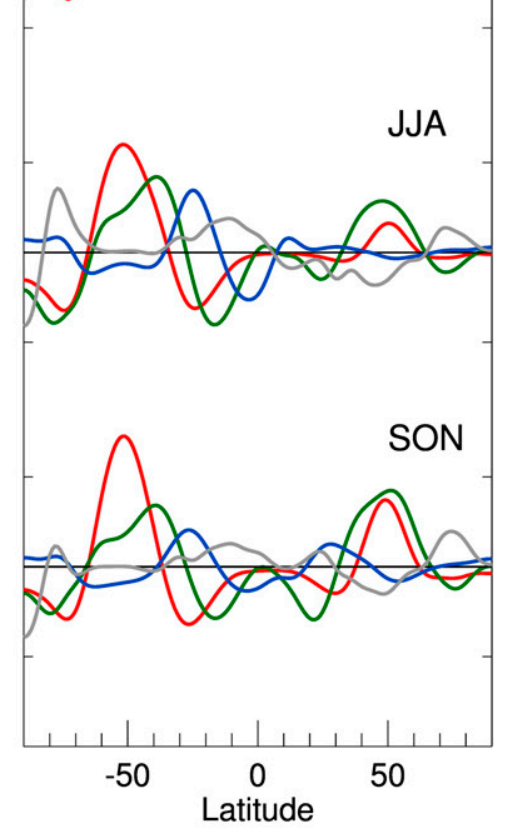

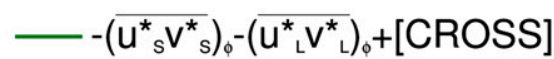

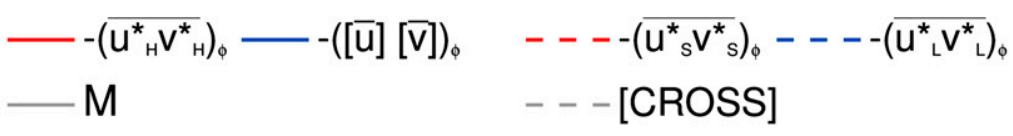

(c) - decomposition

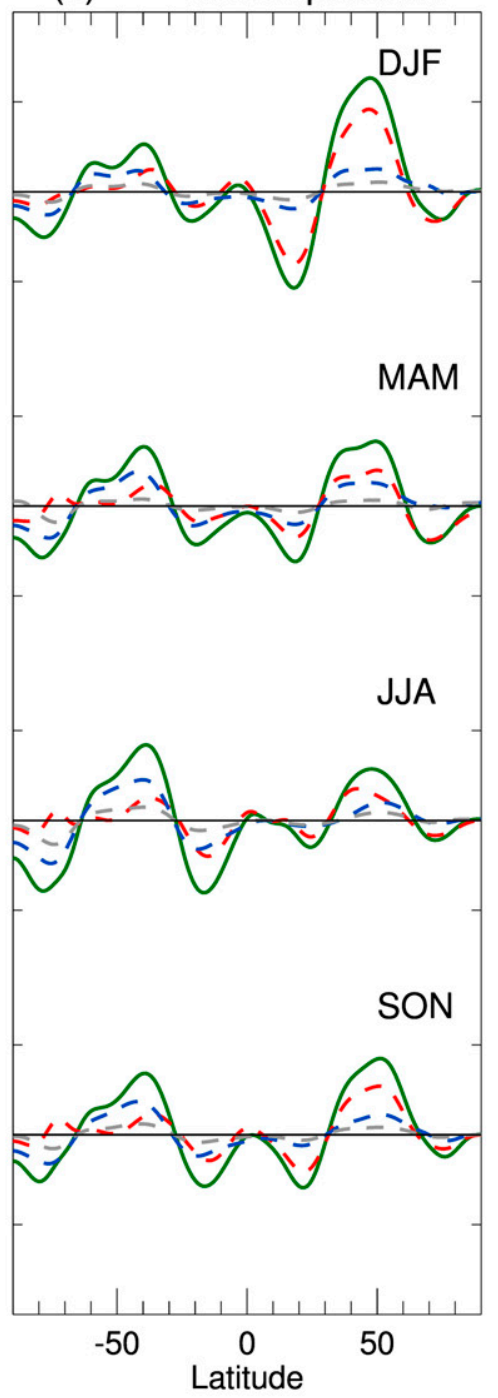

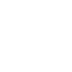

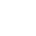


closes reasonably well and a large proportion of the discrepancy in the $\mathrm{NH}$ can be explained by the fact that parameterized processes, in particular gravity wave drag, are not included in the sum (see the appendix). Figure $1 \mathrm{~b}$ decomposes the sum of terms into the contributions from the high-frequency meridional momentum flux, zonal-mean advection, mountain torque, and then the combined stationary, low-frequency, and cross-frequency contribution. This combined contribution is then further decomposed into its individual components in Fig. 1c. The main points to note are as follows.

- In the SH midlatitudes: The high-frequency meridional eddy momentum flux convergence maintains the westerly wind stress. The lower-frequency/stationary eddy momentum flux convergence acts to broaden the jet, particularly on the equatorward side, and this is dominated by the low-frequency component with lesser contributions from the quasi-stationary and cross-frequency component. This tendency for lowerfrequency waves to maintain westerly surface wind stress on the flanks of the jet is expected given that the critical lines for such waves exist farther from the jet center than for the higher-frequency waves (Randel and Held 1991).

- In the NH midlatitudes: While the high-pass transients are important, the low-frequency/stationary contributions are actually more important in maintaining the midlatitude westerlies. This is dominated by the quasistationary component, particularly during winter with a lesser contribution from the low-frequency fluxes.

- In the low latitudes: The zonal-mean momentum flux is large here, but the primary contribution to maintenance of the low-latitude easterlies in the subtropics (i.e., the trade winds) comes from the low-frequency and quasi-stationary momentum fluxes. In the SH these two components are of comparable importance whereas in the $\mathrm{NH}$ the quasi-stationary component tends to dominate. Therefore, the eddy momentum fluxes responsible for maintaining the trades, discussed by Schneider (2006), are stationary and low frequency. This is also true of the budget in the ERAInterim (see the appendix). The eddy momentum flux that contributes to these low-latitude easterlies appears to have components from both equatorwardpropagating waves fluxing easterly momentum into the low latitudes as they are absorbed at their lowlatitude critical line (Randel and Held 1991) and poleward fluxes of easterly momentum in the deep tropics associated with equatorial waves and/or cross-equatorial momentum fluxes associated with the monsoon of the summer hemisphere (Schneider and Watterson 1984; Dima et al. 2005; Shaw 2014) [inferred from the sign of the momentum flux anomalies that contribute to the divergence (not shown)].

The multimodel mean $2 \mathrm{D}$ vertically integrated momentum budgets during the December-February (DJF) and June-August (JJA) seasons for the historical simulations are then shown in Figs. 2 and 3. For brevity, since the focus here is on future predictions, the 2D climatological momentum budget will not be discussed for all seasons. Rather, DJF and JJA are taken here as examples of the balance of terms in the budget and an indication of the degree to which the budget can be closed with the CMIP5 data. The budget will be presented in this form throughout the analysis. The top six panels present the budget and its decomposition with a focus on isolating the contribution of the high-frequency transients from the rest. The sum of terms on the left of (5) is shown in Figs. 2a and 3a and can be compared with $\tau_{u}$ in Figs. $2 \mathrm{~b}$ and $3 \mathrm{~b}$. This is then decomposed into the contributions from the highfrequency fluxes in Figs. 2c,e and 3c,e and the combination of all other terms (STAT + LOW + CROSS) in Figs. $2 \mathrm{~d}$ and $3 \mathrm{~d}$. The residual of the budget is presented in Figs. $2 \mathrm{f}$ and $3 \mathrm{f}$. The contribution from STAT + LOW + CROSS is dominated by STAT and LOW and will be termed the low-frequency-stationary contribution throughout the discussion. This contribution is further decomposed into the quasi-stationary STAT and low-frequency LOW components in the bottom two panels (Figs. $2 \mathrm{~g}$, h and $3 \mathrm{~g}$, h) in each figure. The zonal-mean momentum flux is not shown but can be inferred from Fig. 1.

Comparison of the sum of terms (Figs. 2a and 3a) with $\tau_{u}$ (Figs. 2b and 3b) demonstrates that even the more complex 2D budget can be closed reasonably well with the CMIP5 data. The exceptions lie around steep topography (see the residual in Figs. $2 \mathrm{f}$ and $3 \mathrm{f}$ ) where we do not expect a perfect budget calculation for the reasons outlined in section 2. It should also be noted that the primary contribution to the budget residual comes from the STAT contribution. This is not surprising as this is the most difficult term to accurately calculate since it is the small residual of a balance between much larger terms.

When isolating the contributions from the highfrequency components (Figs. 2c,e and 3c,e), the zonal momentum flux $\left(\overline{\bar{u}_{H}^{\prime} u_{H}^{\prime}}\right)_{\lambda}$ is less unimportant. This is particularly true for the future minus past differences to be shown. This term will be presented for completeness throughout the analysis but will not be discussed in detail.

The main features in Figs. 2a and 3a can be largely attributed to the combination of the high-frequency meridional eddy momentum flux (Figs. 2c and 3c) and 
(a) Sum

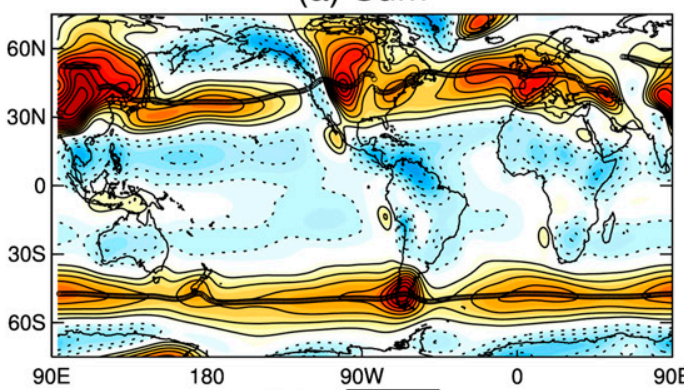

(c) $-\left(\overline{U^{*}{ }_{H} V^{*}}\right)_{\phi}$

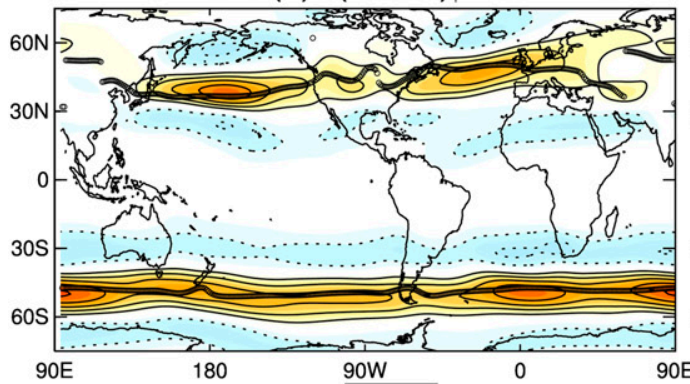

(e) $-\left(\overline{u^{*}{ }_{H} u^{*}}\right)_{\lambda}$

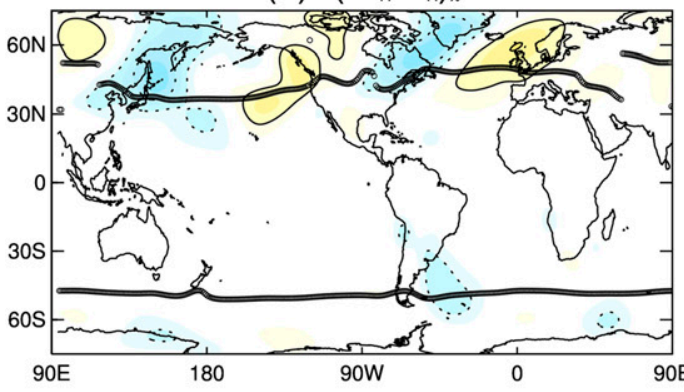

(g) STAT

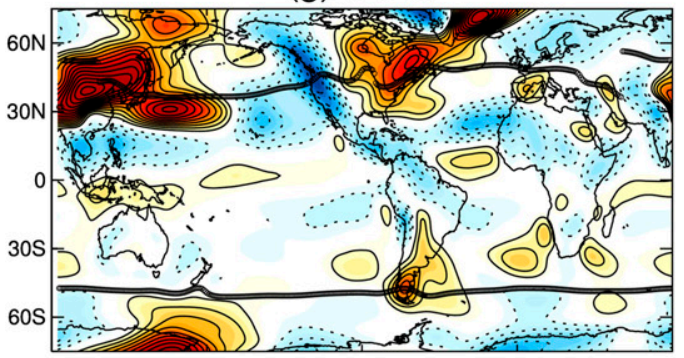

$90 \mathrm{E}$

\section{DJF}

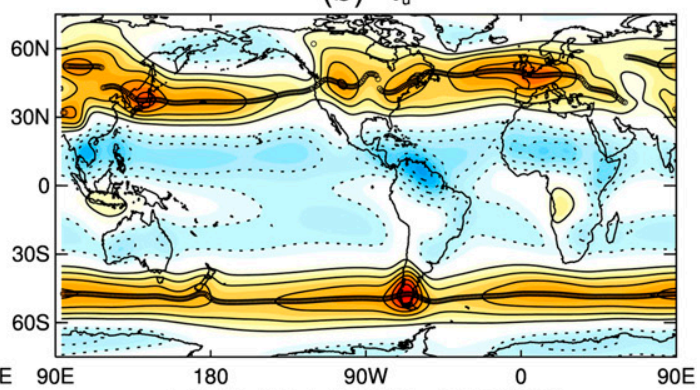

(d) STAT+LOW+CROSS

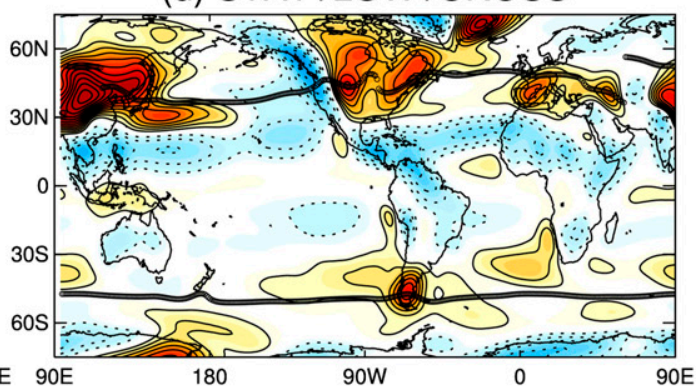

(f) Sum- $\tau_{u}$

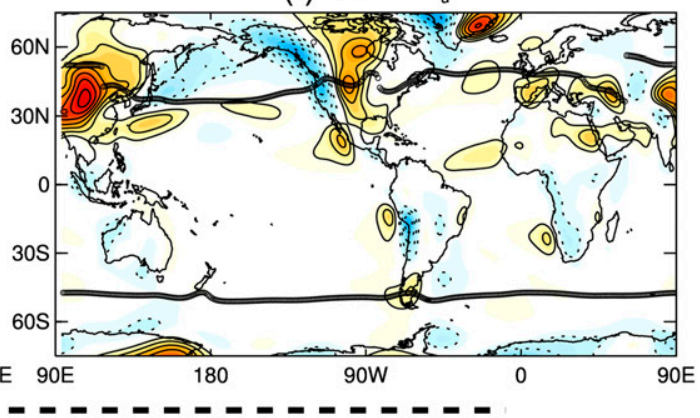

(h) LOW

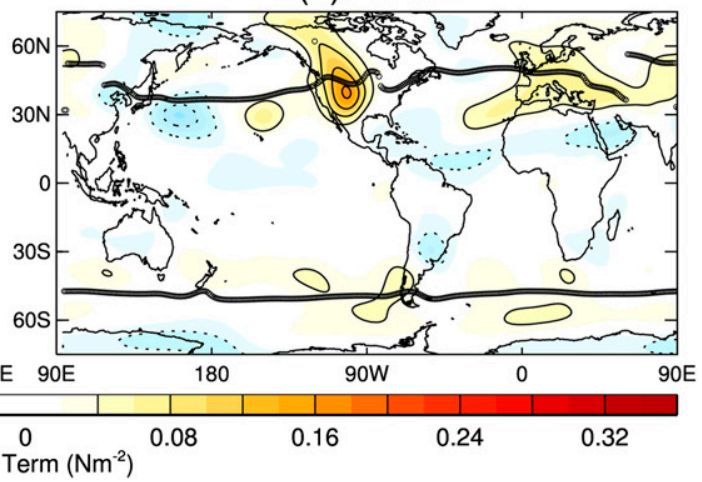

FIG. 2. Multimodel-mean, historical vertically integrated momentum budget terms for the DJF season. (a) The sum of terms in (6); (b) $\tau_{u}$; (c) high-frequency meridional eddy momentum flux; (d) the combination of the STAT, LOW, and CROSS terms; (e) the high-frequency zonal momentum flux; and (f) the residual of the budget [i.e., (a),(b)]. (g),(h) The STAT and LOW contributions that dominate in (d) shown separately. The solid black lines denote the latitude of the maximum $\tau_{u}$ at each longitude. 
(a) Sum

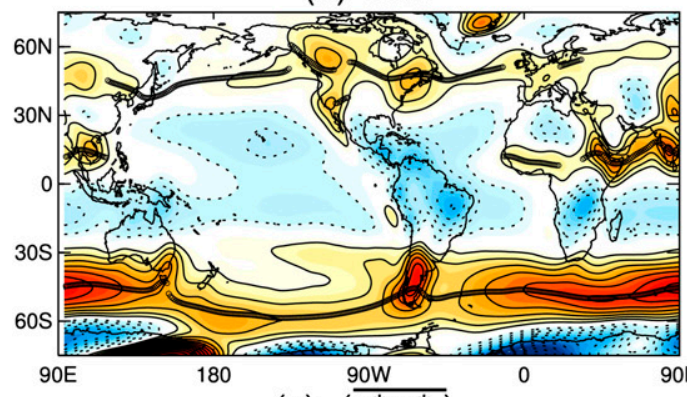

(c) $-\left(\overline{u^{*}{ }_{H} v^{*}}\right)_{\phi}$

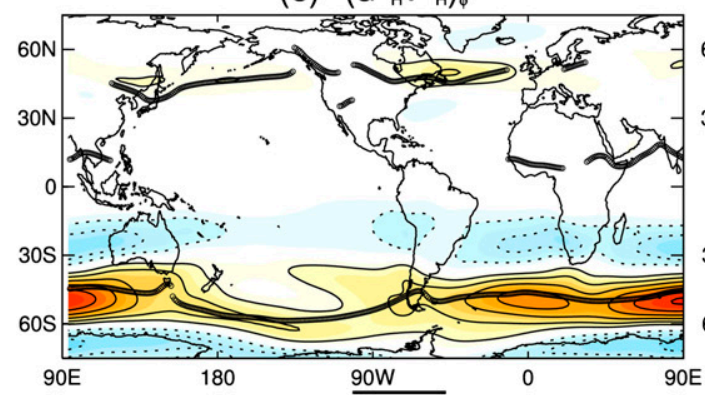

(e) $-\left(\overline{u^{*}{ }_{H} u^{*}}\right)_{\lambda}$

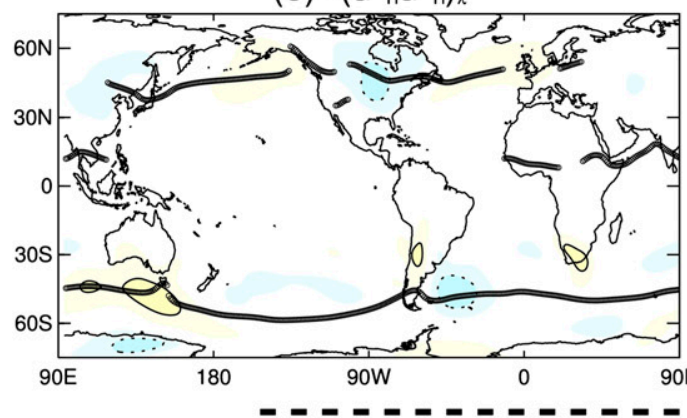

(g) STAT

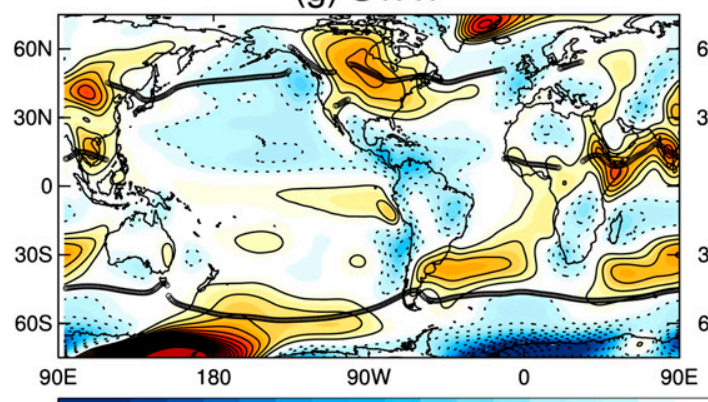

JJA

(b) $\tau_{u}$

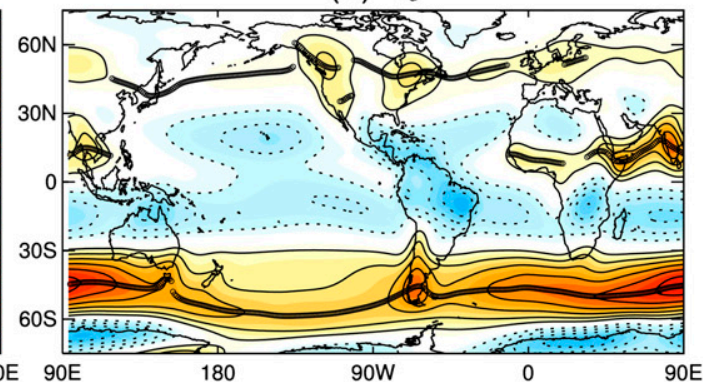

(d) STAT+LOW+CROSS

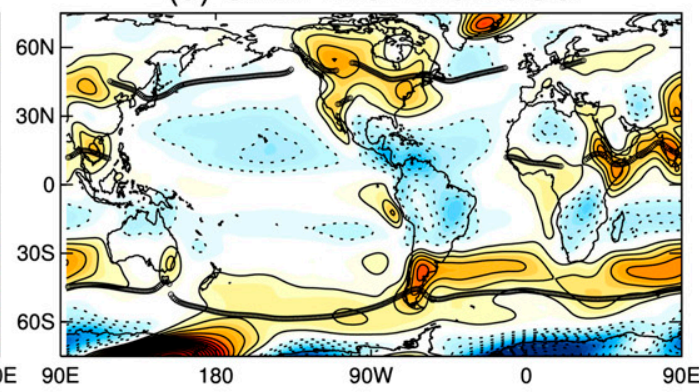

(f) Sum- $\tau_{u}$

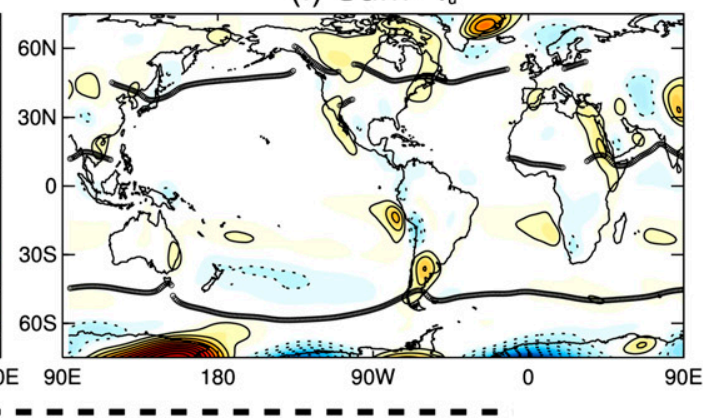

(h) LOW

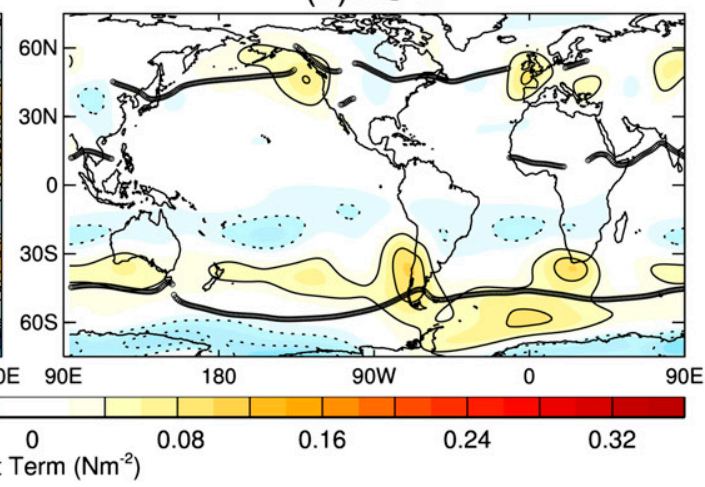

FIG. 3. As in Fig. 2, but for the JJA season.

the stationary component (Figs. $2 \mathrm{~g}$ and $3 \mathrm{~g}$ ) and can be summarized as follows.

- In the SH midlatitudes: Much like in the zonal mean, $-\left(\overline{u_{H}^{\prime} v_{H}^{\prime}}\right)_{\phi}$ (Figs. 2c and 3c) dominates the budget locally and is the primary driver of the westerly surface wind stress. There is also a role for the low-frequency waves (Figs. $2 \mathrm{~h}$ and $3 \mathrm{~h}$ ) in maintaining the westerlies in each season and the quasi-stationary contribution (Figs. $2 \mathrm{~g}$ and $3 \mathrm{~g}$ ) becomes relatively more important in JJA where it acts to drive a westerly surface wind stress in the South Atlantic and southern Indian Ocean. 
- In the NH midlatitudes: There is a dominant role for $-\left(\overline{u_{H}^{\prime} v_{H}^{\prime}}\right)_{\phi}$ in maintaining $\tau_{u}$ locally in the storm-track regions but there are also substantial contributions from the low-frequency/stationary eddy terms (Figs. $2 \mathrm{~d}$ and $3 \mathrm{~d}$ ), which primarily contribute to the westerly surface wind stress at the entrance of the storm tracks (more so in winter). The further decomposition of this contribution into the STAT and LOW components demonstrate that this is primarily due to the quasistationary motions (Figs. $2 \mathrm{~g}$ and $3 \mathrm{~g}$ ). The structure of this stationary eddy term comes from the existence and shape of the stationary waves that arise from orography, land-sea contrasts, and diabatic heating (Held et al. 2002; Brayshaw et al. 2009; Kaspi and Schneider 2013). The low frequencies primarily contribute to the budget at the exit of the storm tracks where they result in a westerly surface wind stress.

- In the low latitudes: The easterly wind stress that prevails in the subtropical ocean basins in the $\mathrm{NH}$ is primarily maintained by the stationary and lowfrequency eddy terms (Figs. 2d and 3d) (as also seen in the zonal mean in Fig. 1). This is primarily associated with the STAT contribution although there is a lesser role for the LOW contribution over North Africa [primarily associated with the $-\left(\overline{u_{L}^{*} v_{L}^{*}}\right)_{\phi}$ component (not shown)]. In the SH low latitudes, it is a mixture of $-\left(\overline{u_{H}^{\prime} v_{H}^{\prime}}\right)_{\phi}$, LOW, STAT, and the zonal-mean momentum flux that is responsible for maintaining the low latitude easterlies.

To summarize, the vertically integrated momentum budget can be closed rather well with the available data in the CMIP5 archive both in the zonal mean and locally in the latitude-longitude plane. We proceed to make use of these budget calculations to diagnose the model predictions for the future of the midlatitude circulation.

\section{Future changes in the zonal-mean zonal wind}

We begin with an assessment of the future changes in lower-tropospheric $(700 \mathrm{hPa})$ zonal-mean zonal wind: a common metric for assessing future changes in the barotropic component of the midlatitude westerlies. This is shown for the 35 models listed in Table 1 in Fig. 4 along with the climatological zonal-mean zonal wind and jet latitude for comparison. Comparing the climatological zonal wind (red line) with the future-past difference (black line) it can be seen that the future changes are on the order of $10 \%$ of the climatology in the midlatitudes. Figure 4 demonstrates, as found in previous studies, that the dominant response of the midlatitude jet in the $\mathrm{SH}$ is a statistically significant dipole surrounding the jet maximum in the sense of a poleward shift but with the positive part being larger than the

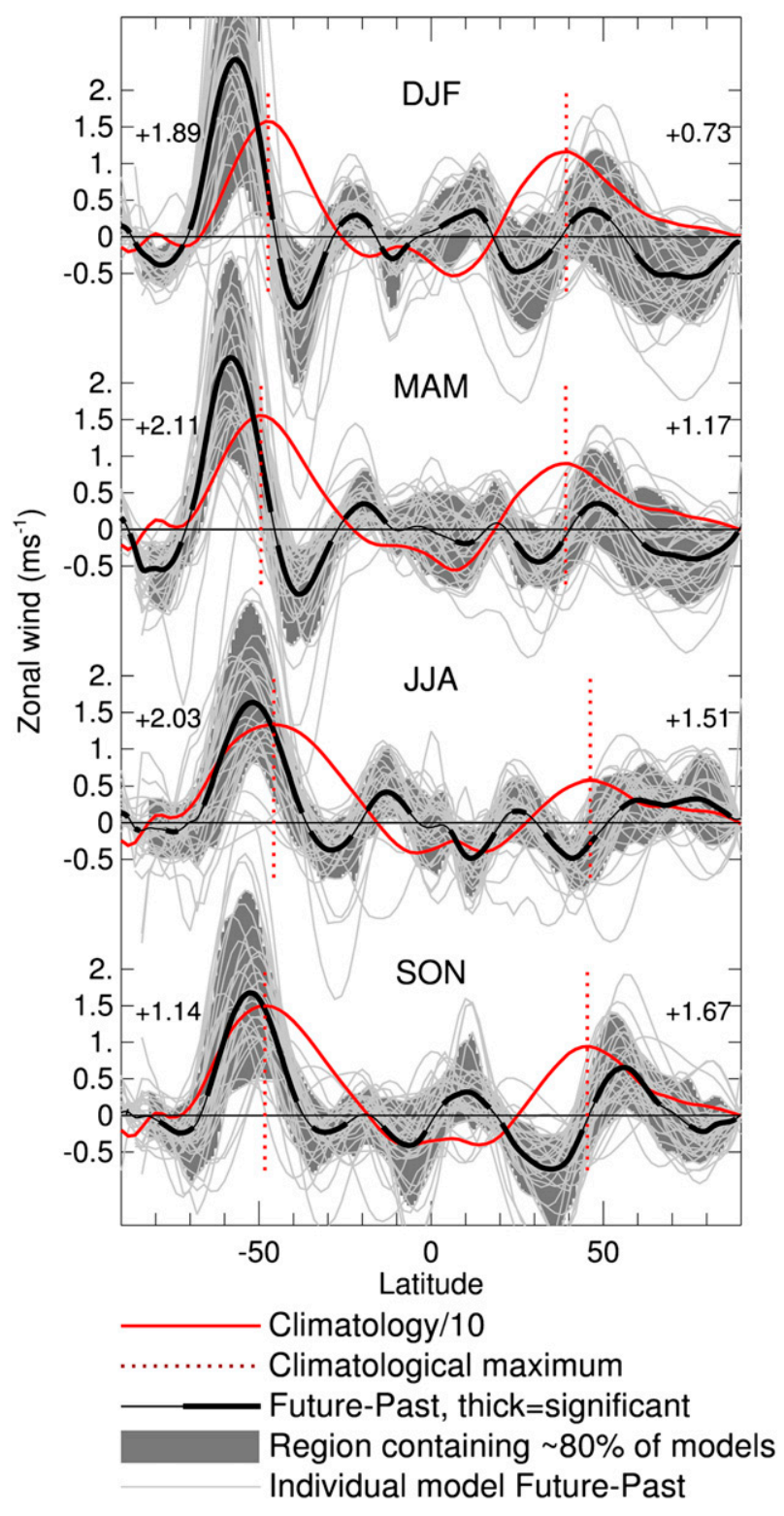

FIG. 4. Zonal-mean zonal wind at $700 \mathrm{hPa}$ for each season for the 35 models listed in Table 1. See legend for definitions. The climatological jet maximum latitude and its shift are listed for each hemisphere and season. These were obtained for each individual model before taking the multimodel mean and were calculated using a least squares quadratic fit to the three points around the latitude of maximum wind speed. Significance is defined as where the anomalies are statistically different from zero by a two-tailed $t$ test.

negative. The SH zonal wind anomalies are largest in DJF and March-May (MAM) demonstrating that, in this high-emissions scenario and late in the century (2070-99), the poleward shift of the SH jet due to increasing greenhouse gases clearly dominates over the equatorward shift of the jet expected owing to ozone 
recovery (Arblaster and Meehl 2006; McLandress et al. 2011; Polvani et al. 2011). Note that in JJA, while the zonal wind anomalies are smaller, they bring about a larger shift in the jet maximum than in DJF, owing to the difference in structure of the historical jet.

The midlatitude zonal-mean zonal wind anomalies in the $\mathrm{NH}$ are, in general, smaller than those in the SH. Nevertheless, the zonal-mean jet shifts poleward in each season and the anomalies are significantly different from zero, albeit with a large spread among the models. The SON season has both the largest zonal wind anomalies and the largest poleward shift of the jet, as also noted by Gillett and Fyfe (2013) and Barnes and Polvani (2013).

The zonal-mean vertically integrated momentum budget for the 13 models highlighted in boldface in Table 1 is shown in Fig. 5. Figure 5a demonstrates that $\tau_{u}$ changes in a similar same way to the $700-\mathrm{hPa}$ zonal wind of the 35 models in Fig. 4, indicating that the mean response of the 35 models is largely captured by this 13 -model subset and that $\tau_{u}$ responds in a similar way to the lowertropospheric zonal-mean zonal wind, as expected. Furthermore, the future minus past difference in $\tau_{u}$ is captured well by the sum of terms in (13).

The various components that contribute to the zonalmean vertically integrated momentum budget are shown in the remaining panels of Fig. 5. The change in CROSS is not shown here as it is small. Comparing the $\tau_{u}$ response in Fig. 5a with the $-\left(\overline{u_{H}^{\prime} v_{H}^{\prime}}\right)_{\phi}$ contribution in Fig. $5 \mathrm{~b}$ it is clear that, in the extratropics for the multimodel mean, the dominant term in maintaining the anomalous surface wind stress is the high-frequency meridional eddy momentum flux convergence. In terms of the latitudinal shift of the jet, the high-frequency eddy momentum flux convergence, if acting alone, would actually cause a larger poleward shift than observed. The shift due to $-\left(\overline{u_{H}^{*} v_{H}^{*}}\right)_{\phi}$ acting alone is quoted for each hemisphere in Fig. $5 \mathrm{~b}$ by taking the future wind to be the historical wind stress $\tau_{u}$ plus the future wind stress change due to the change in $-\left(\overline{u_{H}^{*} v_{H}^{*}}\right)_{\phi}$; that is, $\tau_{u}+\Delta\left[-\left|\left(\overline{u_{H}^{*} v_{H}^{*}}\right)_{\phi}\right|\right]$ [see Eq. (13)].

The changes in the other terms are, however, nonnegligible. In the NH tropics, climatologically the quasistationary component (Fig. 5c) contributes to the easterly $\tau_{u}$ of the trade winds and this seems to weaken in the future (i.e., the quasi-stationary component provides an anomalous westerly tendency). Other than that, it has the effect of broadening and strengthening the dipole in zonal wind anomalies that occur around the jet center. But, in the $\mathrm{NH}$ extratropics there appears to be some cancellation between this contribution and that of the mountain torque. The lower-frequency contribution is smaller, but of comparable importance to the quasi-stationary component in the SH. Finally, there is a tendency, in the winter hemisphere in particular, for the zonal-mean momentum flux convergence to consist of a poleward shift of the climatological maximum, which is likely a signature of the poleward expansion of the tropics and the Hadley cell in the winter hemisphere.

To summarize, the poleward shift of the zonal-mean westerly surface wind stress seen in each hemisphere and season is predominantly maintained by anomalous high-frequency meridional eddy momentum flux convergence, but the overall zonal-mean wind response includes additional, nonnegligible contributions from the other components.

\section{Zonal asymmetries in future zonal wind changes}

The above zonal-mean analysis has confirmed the results of previous studies that a poleward shifting of the zonal-mean zonal wind occurs in each hemisphere and season in response to global warming, and has quantified the role of high-frequency transient meridional momentum fluxes in maintaining this circulation response. We now assess the 2D zonal wind changes and momentum budget. The first question we ask is: does the poleward shifting of the midlatitude westerlies prevalent in the zonal mean, also occur locally at each longitude?

\section{a. The Southern Hemisphere}

Beginning with the $\mathrm{SH}$, the $700-\mathrm{hPa}$ zonal wind anomalies for each season are shown in the first column of Fig. 6 and the model consensus on the sign of the response is shown in the second column. This produces similar features to Lorenz and DeWeaver (2007)'s analysis of the CMIP3 models (see their Fig. 4). DJF and MAM are when the SH jet is most zonally symmetric and when the zonal-mean anomalies maximize (Fig. 4). In these seasons there truly is a zonally symmetric poleward shifting of the SH jet (Figs. 6a and 6c).

The zonal wind changes are more complicated in JJA and September-November (SON). Climatologically, the $\mathrm{SH}$ jet is less zonally symmetric in these seasons, particularly in JJA, where the jet splits to the east of New Zealand (Bals-Elsholz et al. 2001; Inatsu and Hoskins 2004; Hoskins and Hodges 2005). In these seasons, the shift in the zonal mean is actually an average over considerable zonal asymmetry, owing primarily to the asymmetry in the climatological jet. South and east of New Zealand where the climatological jet is farther poleward, the shift of the jet in JJA and SON is actually equatorward.

\section{b. The Northern Hemisphere}

In the $\mathrm{NH}$, there is substantial zonal asymmetry and seasonal variation in the change in the zonal winds, as seen in Fig. 7. This largely agrees with the results of Lorenz and 
(a) $\tau$ and Sum

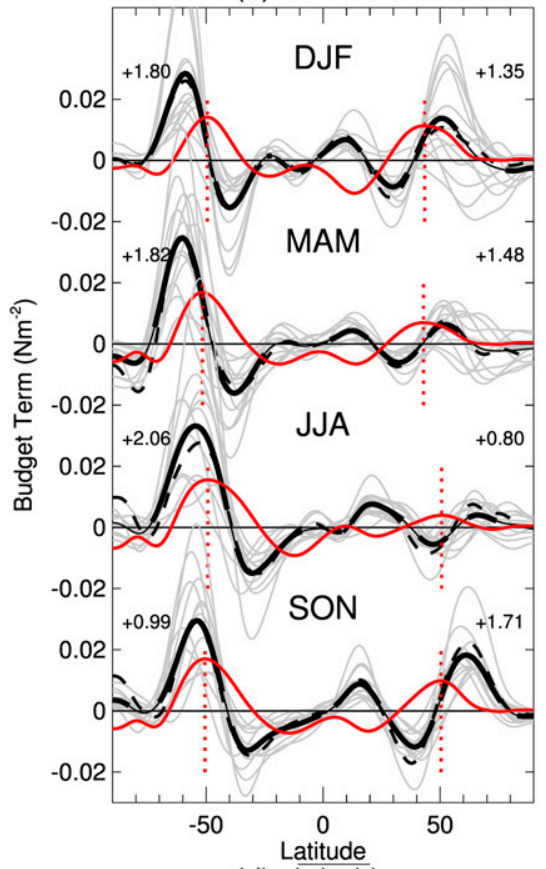

(d) $-\left(\mathrm{u}^{*}{ }_{\mathrm{L}} \mathrm{V}^{*}\right)_{\mathrm{Q}}$

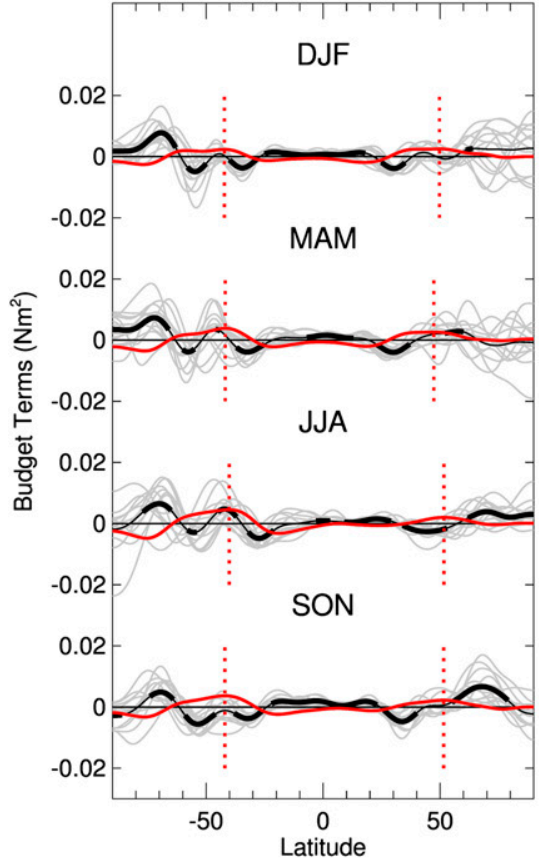

Climatology $/ 10$ (b) $-\left(\overline{u^{\star}{ }_{H} v^{*}}\right)_{0}$

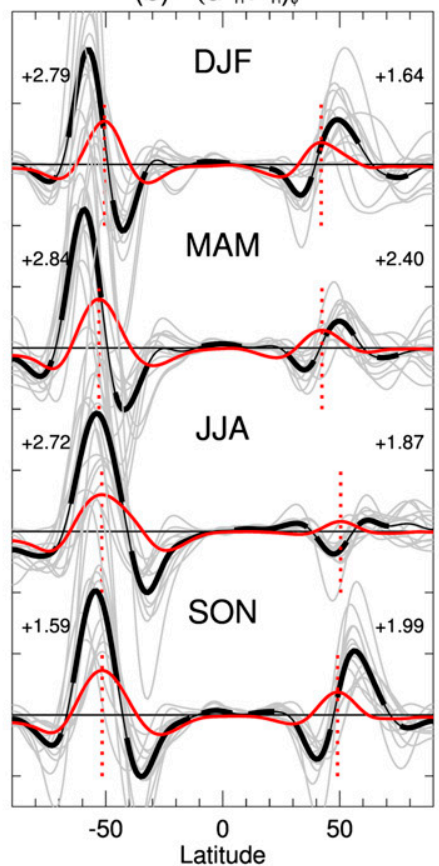

(e) $-([\mathrm{u}][\mathrm{v}])_{\text {。 }}$

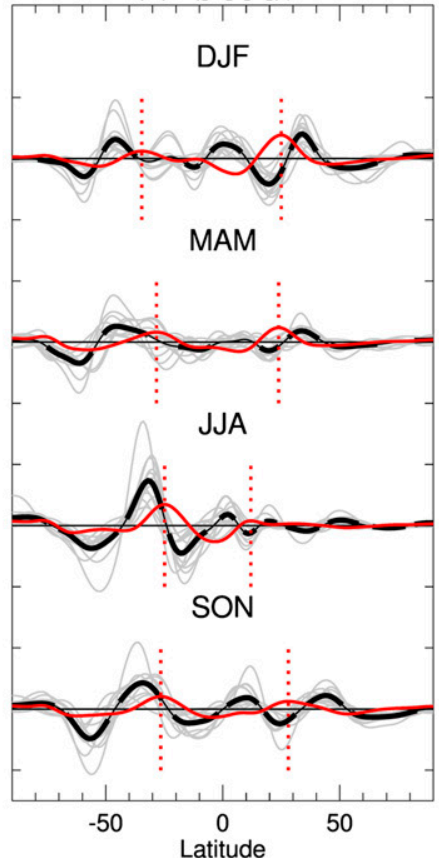

Climatological maximum (c) $-\left(\overline{u^{*}{ }_{s} v^{*}{ }_{s}}\right)_{0}$

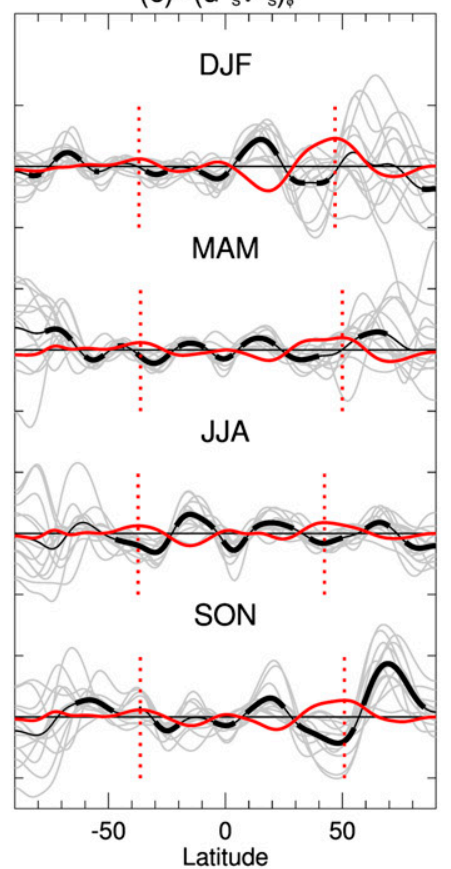

(f) Mountain

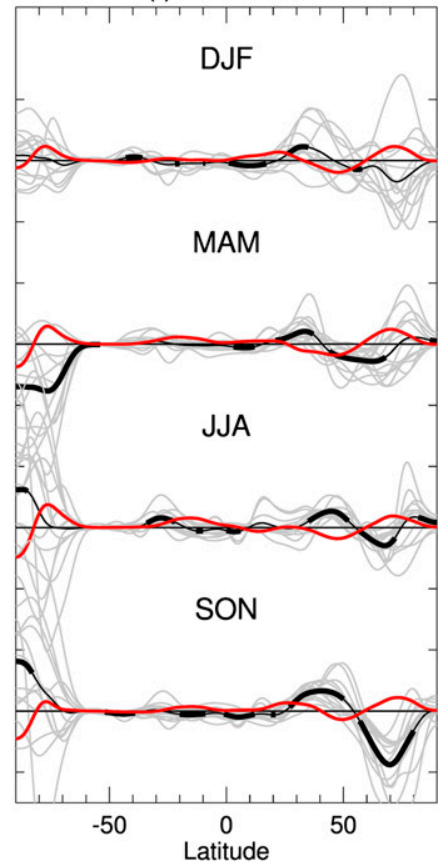

Individual models, difference

\section{Multi-model mean, Future-Past difference, thick=significant}

FIG. 5. The future minus past difference in each of the vertically integrated zonal-mean momentum budget terms in (13) for (top to bottom) each season. Future minus past difference (black), climatology/10 (solid red), location of the climatological maximum wind stress or momentum flux convergence (vertical red dashed), and difference for each individual model (gray). (a) $\bar{\tau}_{u}$ along with the sum of budget terms (black dashed), (b) $-\left(\overline{u_{H}^{*} v_{H}^{*}}\right)_{\phi},(\mathrm{c})-\left(\overline{u_{S}^{*} v_{S}^{*}}\right)_{\phi},(\mathrm{d})-\left(\overline{u_{L}^{*} v_{L}^{*}}\right)_{\phi},(\mathrm{e})-([\bar{u}][\bar{v}])_{\phi}$, and (f) mountain torque. Poleward shifts of $\bar{\tau}_{u}$ are listed in (a) and the shift in $\bar{\tau}_{u}$ due to the $-\left(\overline{u_{H}^{*} v_{H}^{*}}\right)_{\phi}$ term alone is shown in (b). This is obtained by taking the future $\tau_{u}$ to consist of the past $\tau_{u}$ plus the implied future wind stress due to the $-\left(\overline{u_{H}^{\prime} v_{H}^{\prime}}\right)_{\phi}$ change. Significance is defined as where the anomalies are statistically different from 0 at the $95 \%$ level by a two-tailed $t$ test. 
(a) $700 \mathrm{hPa}$ zonal wind, DJF

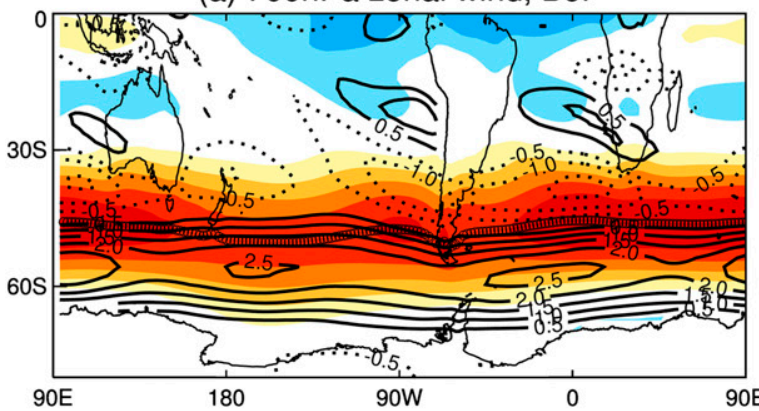

(c) $700 \mathrm{hPa}$ zonal wind, MAM

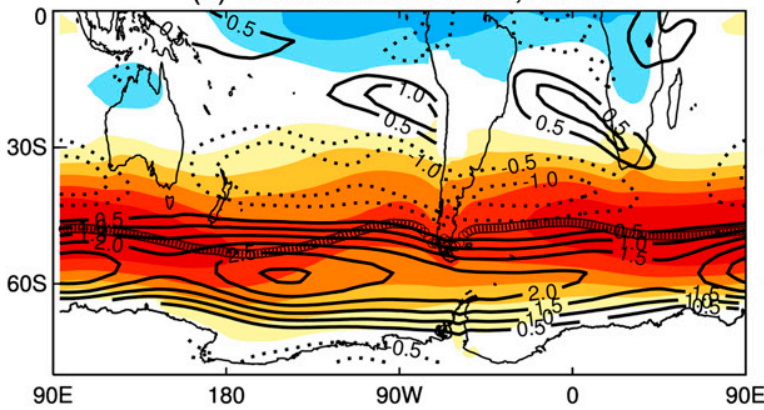

(e) $700 \mathrm{hPa}$ zonal wind, JJA

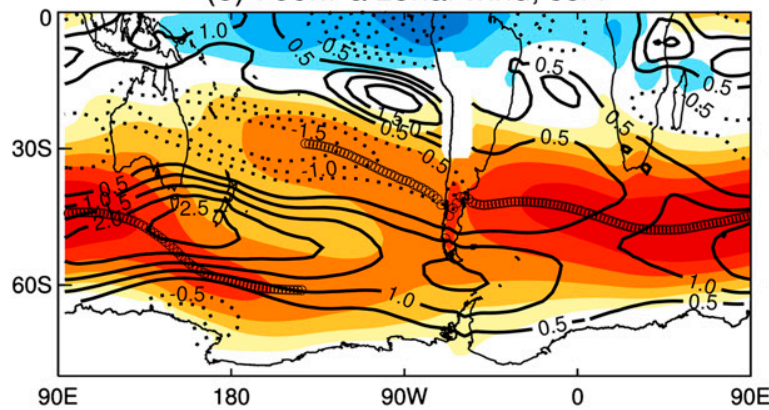

(g) $700 \mathrm{hPa}$ zonal wind, SON

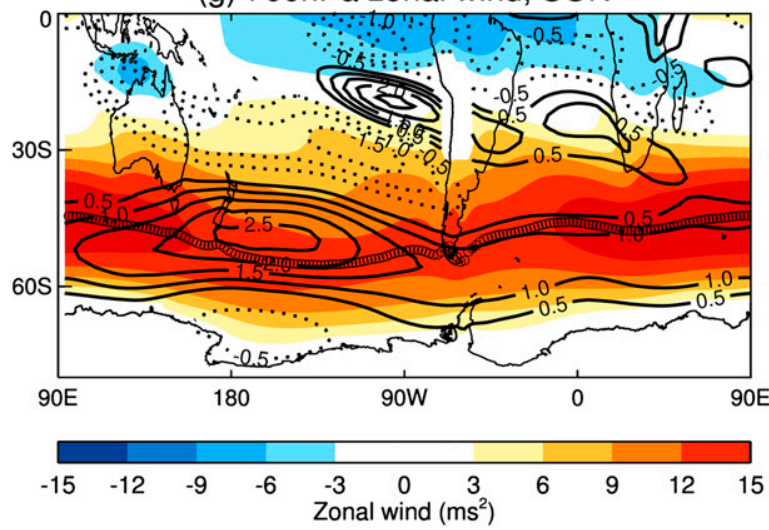

(b) Model consensus, DJF

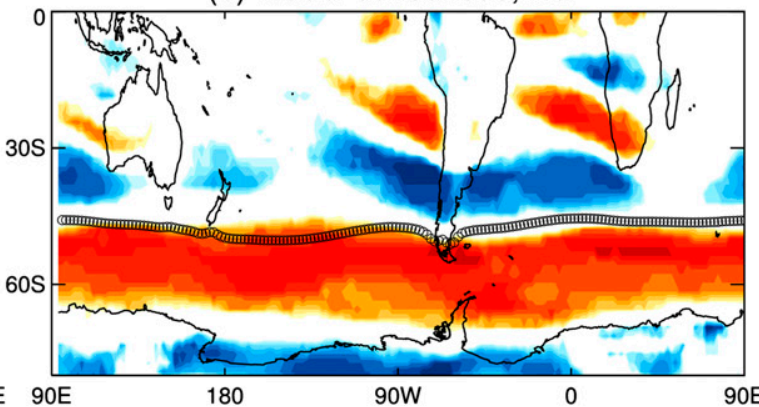

(d) Model consensus, MAM

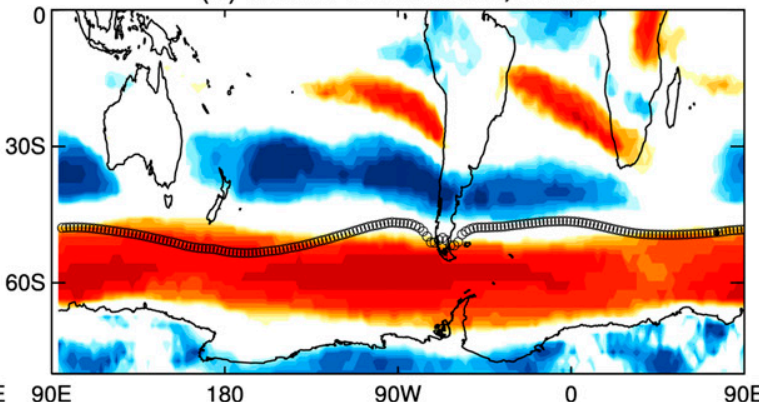

(f) Model consensus, JJA

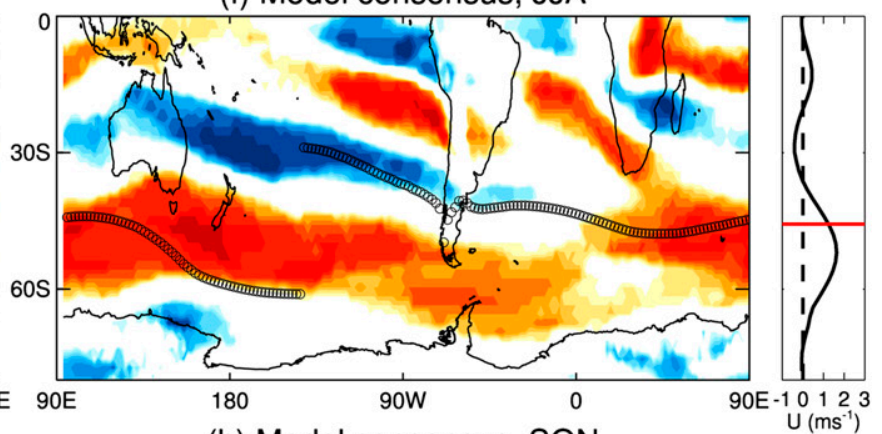

(h) Model consensus, SON

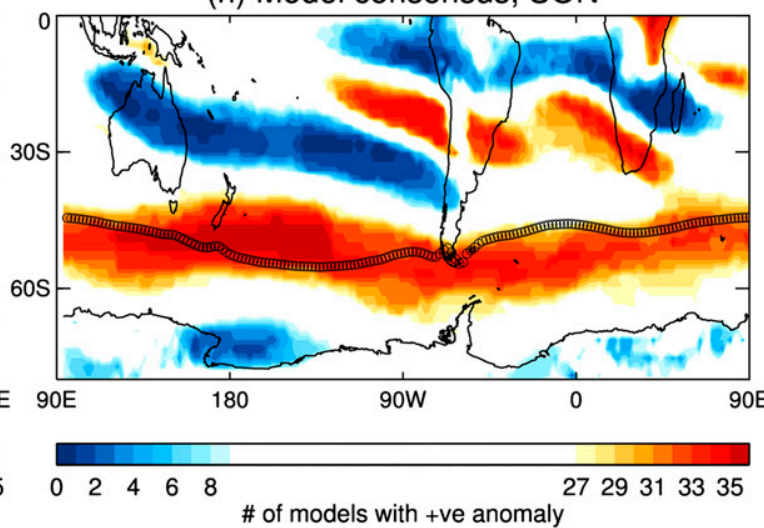

Zonal Mean

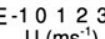
$\mathrm{U}\left(\mathrm{ms}^{-1}\right)$

OE-10 123 $\mathrm{U}\left(\mathrm{ms}^{-1}\right)$
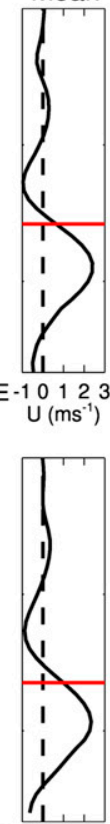

FIG. 6. (a),(c),(e),(g) The future minus past difference in 700-hPa zonal wind in the SH (contours) along with the climatology (shading) and the climatological jet maximum at each longitude (small black overlapping circles) for the DJF, MAM, JJA, and SON seasons, respectively. (b),(d),(f),(h) The model consensus on the sign of the zonal wind anomalies for each season. (right) The zonal-mean 700-hPa zonal wind response for reference. 
(a) $700 \mathrm{hPa}$ zonal wind, DJF

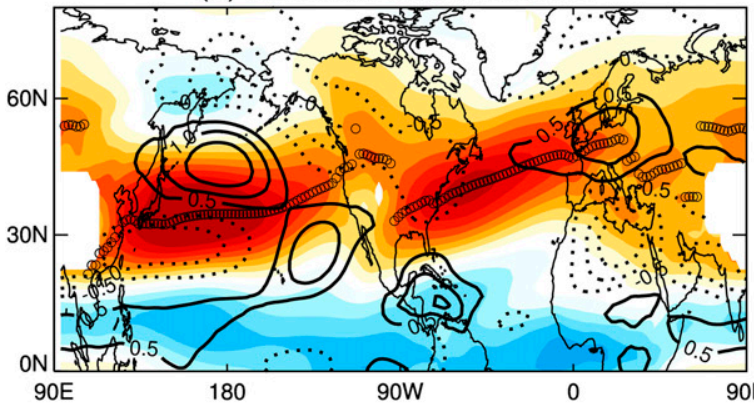

(c) $700 \mathrm{hPa}$ zonal wind, MAM

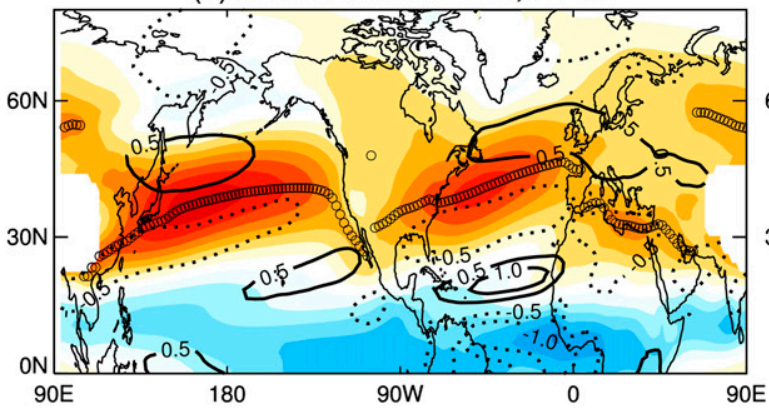

(e) $700 \mathrm{hPa}$ zonal wind, JJA

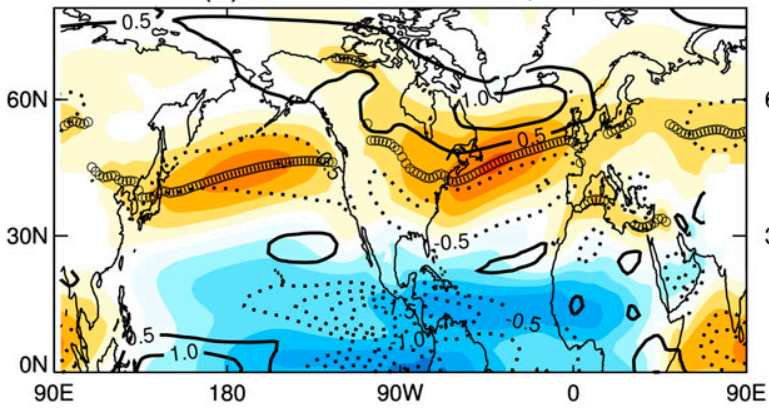

(g) $700 \mathrm{hPa}$ zonal wind, SON

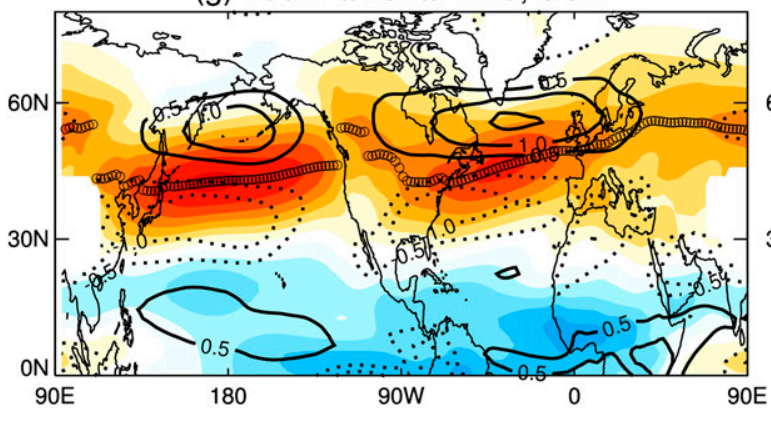

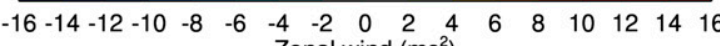
Zonal wind $\left(\mathrm{ms}^{2}\right)$ (b) Model consensus, DJF

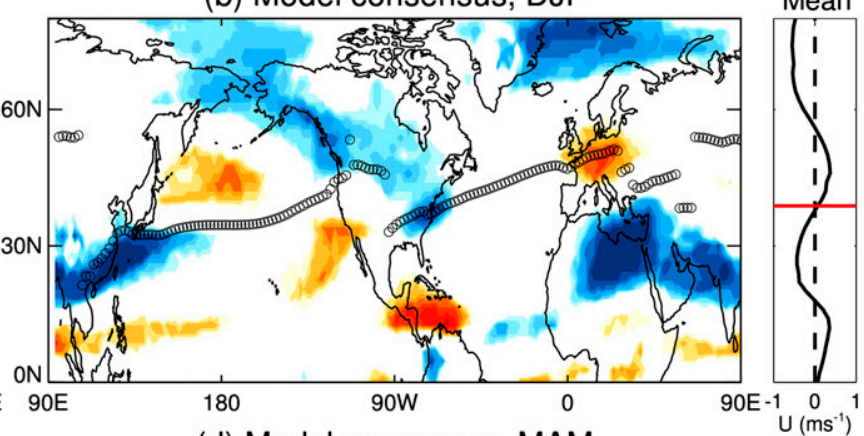

(d) Model consensus, MAM

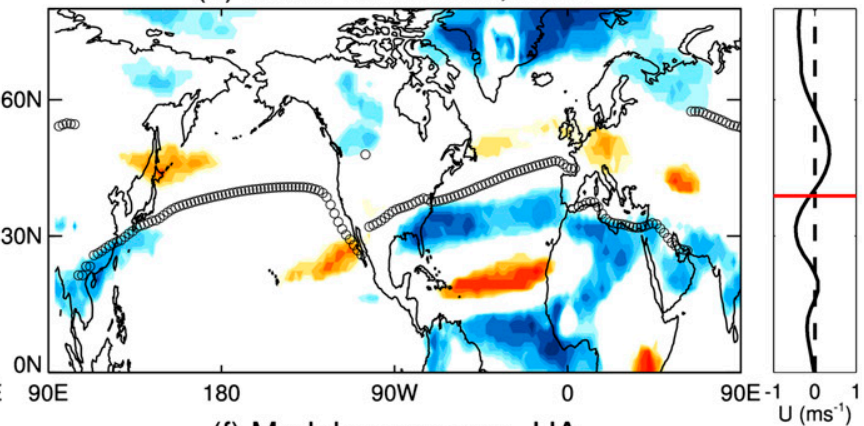

(f) Model consensus, JJA

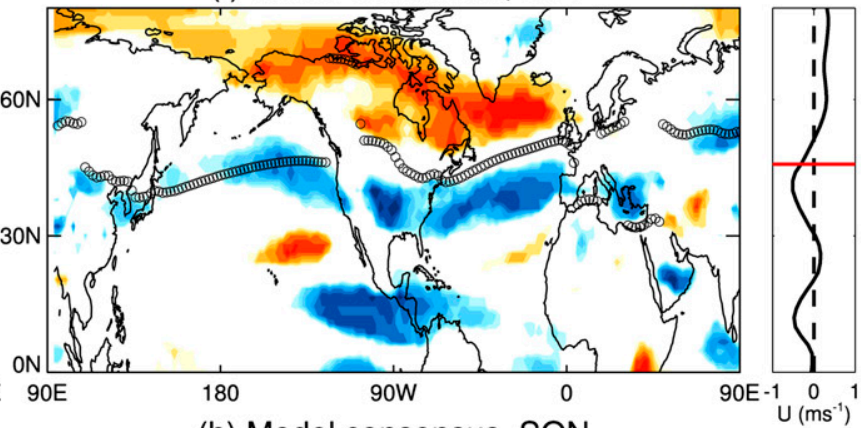

(h) Model consensus, SON

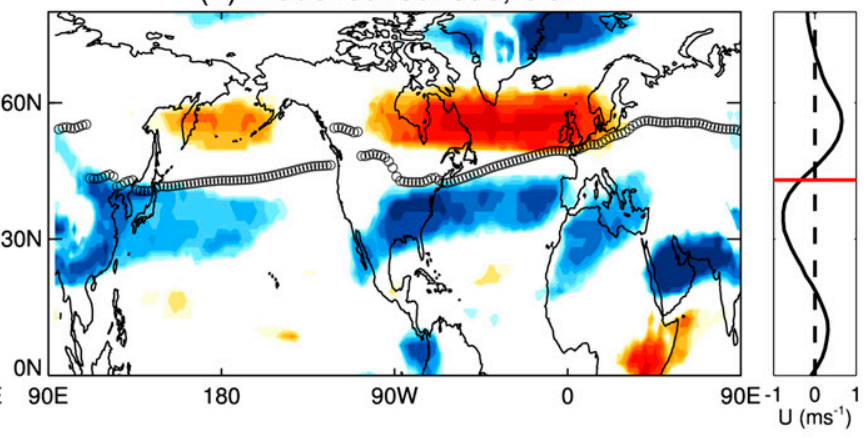

29313335

FIG. 7. As in Fig. 6, but for the NH.

DeWeaver (2007) for the CMIP3 models, with the exception of the anomalies in the east Pacific in DJF, which were not so apparent in the CMIP3 A2 scenario (Lorenz and DeWeaver 2007; Neelin et al. 2013).
The zonal wind response during SON is the most zonally symmetric (Figs. $7 \mathrm{~g}$ and $7 \mathrm{~h}$ ), consistent with the largest zonal-mean response in the $\mathrm{NH}$ occurring in this season (Fig. 4). There is a poleward shift of both the 
Atlantic and Pacific jets with a strong model consensus. This is also true in MAM, but the anomalies are much weaker and there is less of a consensus. During JJA, while the zonal-mean jet shifts poleward, Figs. $7 \mathrm{e}$ and $7 \mathrm{f}$ show that, locally, it is only the Atlantic jet that is shifting poleward while the Pacific jet is mostly weakening.

The DJF season is the most complex season for the $\mathrm{NH}$ zonal wind response. In the zonal mean, the anomalies exhibit a dipole and a poleward shift of the zonal-mean jet maximum (see Fig. 4). However, Fig. 7a makes clear that this interpretation is only true locally in the west Pacific. In the east Pacific, the jet is actually shifting equatorward. In the west Atlantic, there is very little consensus among the models, but to the east there is a consensus on a strengthened westerly wind at the jet exit region across the British Isles and France and a weakened westerly wind over North Africa. This anomaly would actually appear as a poleward shift of the Atlantic jet in a basin-mean analysis across the Atlantic owing to the southwest-northeast tilt of the Atlantic jet, but this is more properly characterized as a strengthening of the jet exit and a weakened zonal wind much farther south over North Africa. This feature has been discussed by Woollings and Blackburn (2012) for CMIP3 and Harvey et al. (2012) note a corresponding strengthening of storm activity at the jet exit in the CMIP5 models.

The shift of the Atlantic and Pacific jets as a function of longitude and day of the year is summarized in Fig. 8. There is a clear consensus of a poleward shift of each jet across each basin in the fall, with up to a $3^{\circ}$ or $4^{\circ}$ shift in the west Atlantic. The months of strongest consensus, however, differ slightly between the Atlantic and $\mathrm{Pa}-$ cific. In winter, there is very little shift of the Atlantic jet but the Pacific jet shows consensus on a poleward shift in the west and an equatorward shift in the east. There is also some consensus on a slight equatorward shift of the Pacific jet in July in the west.

The NH midlatitude circulation response is complex and it is important to understand these particular localized features, which do not fit our typical interpretation of a poleward shifting of the midlatitude circulation under climate change.

\section{Future changes in the two-dimensional vertically integrated momentum budget}

The two-dimensional vertically integrated momentum budgets for the future minus past difference in the SON, DJF, MAM, and JJA seasons are shown in Figs. 9, 10,11 , and 12 , respectively. The $\tau_{u}$ responses of the 13model subset (Figs. 9b, 10b, 11b, and 12b) resemble that of the 700-hPa zonal wind in the 35-model mean. Bear in mind the features of strong model consensus in the $700-\mathrm{hPa}$
(a)Pacific jet shift

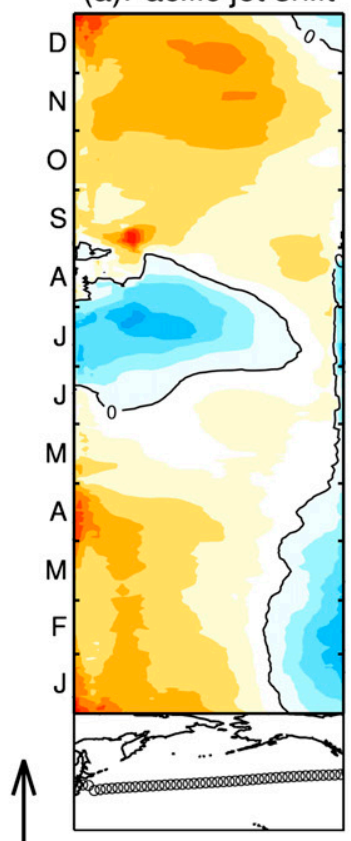

(b)Atlantic jet shift

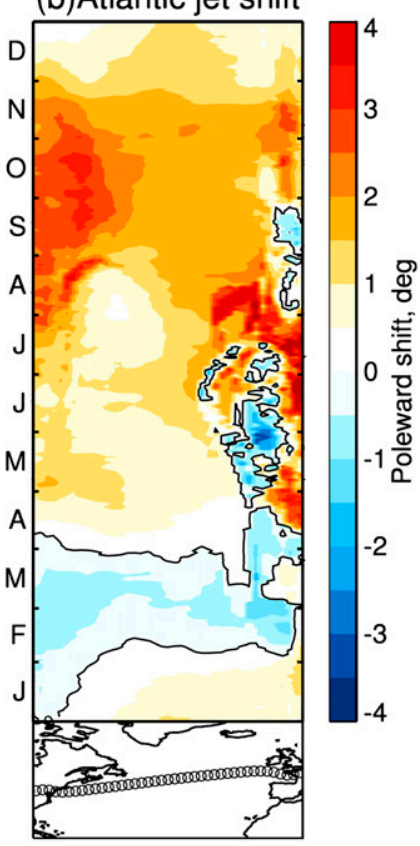

(c)Pacific consensus (d)Atlantic consensus

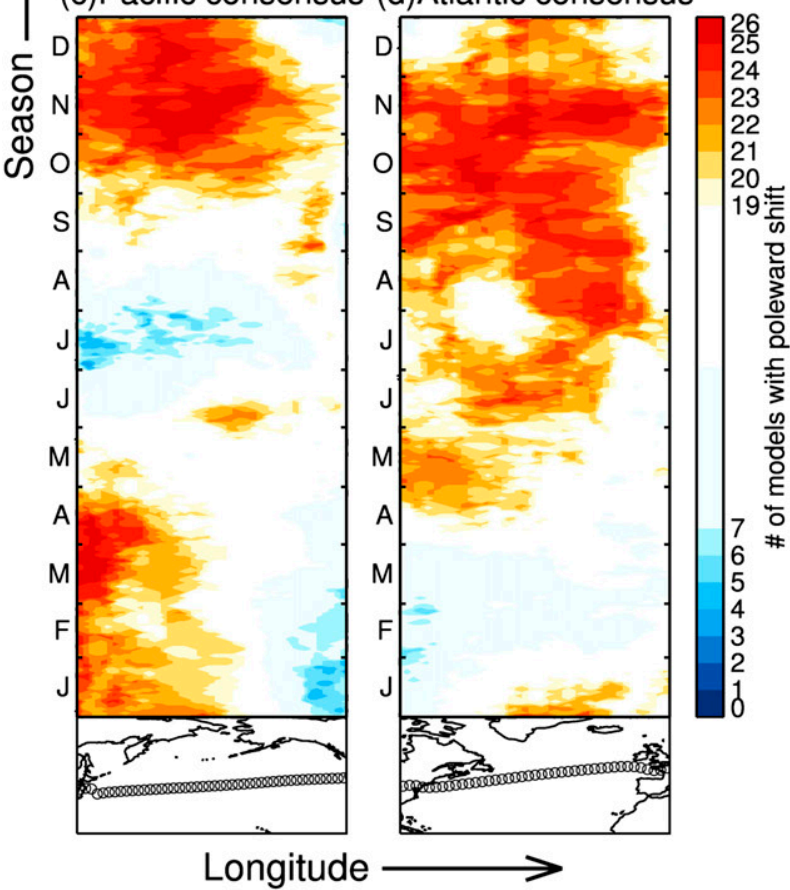

FIG. 8. The jet shift in (a) the Pacific basin and (b) the Atlantic basin as a function of longitude and month. These plots make use of the daily data summarized in Table 1 and a 30-day running mean is applied over the seasonal cycle before the jet latitude is calculated. Jet latitude is calculated from a quadratic fit to the three points around the latitude of maximum $700-\mathrm{hPa}$ wind and the jet shift is calculated for each model individually before taking the ensemble mean. (c),(d) The model consensus for the jet shift. The panels below the colored panels indicate the longitudes shown, and the small black overlapping circles denote the historical jet latitude at each location. 
(a) Sum all terms

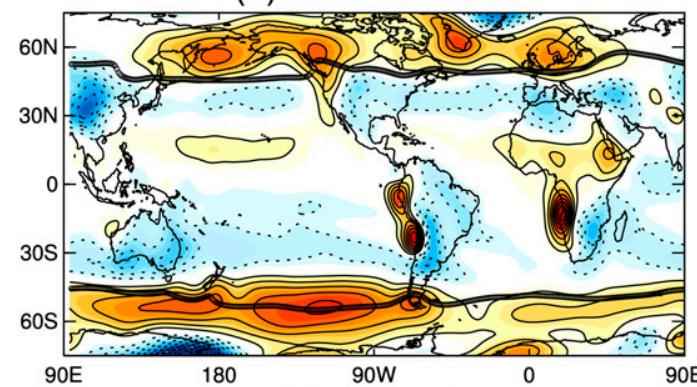

(c) $-\left(\overline{\left.U^{*}{ }^{*} V^{*}\right)_{0}}\right.$

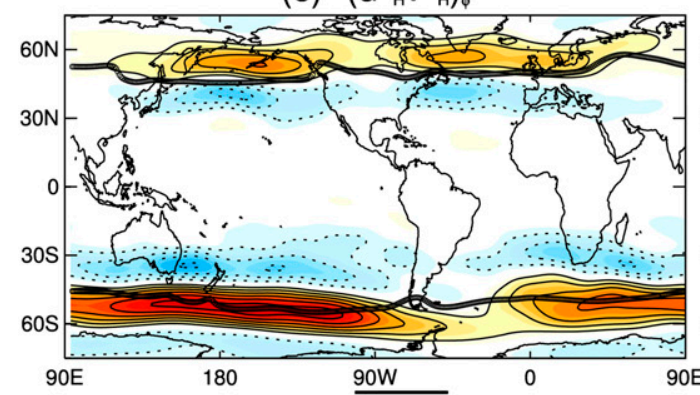

(e) $-\left(\overline{\mathrm{u}^{*}{ }_{H} \mathrm{U}^{*}{ }_{\mathrm{H}}}\right)_{\lambda}$

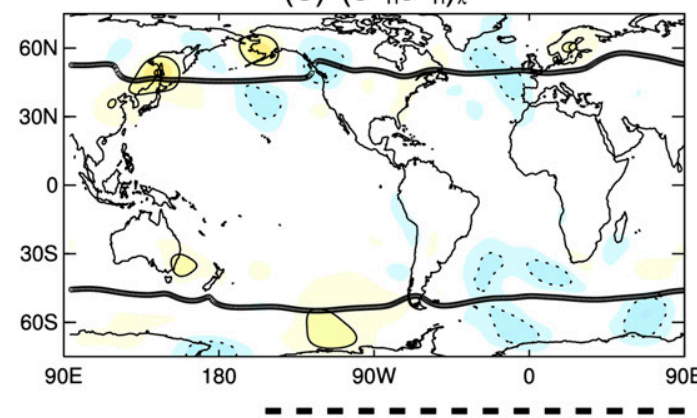

(g) STAT

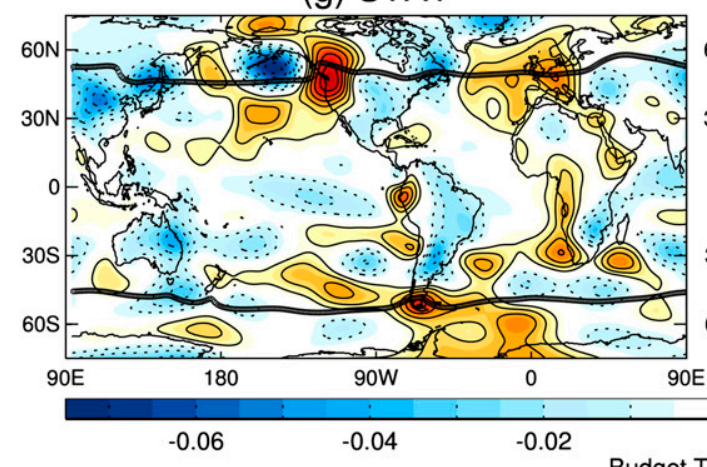

Budget Term $\left(\mathrm{Nm}^{-2}\right)$
SON $\quad$ (b) $\tau_{u}$

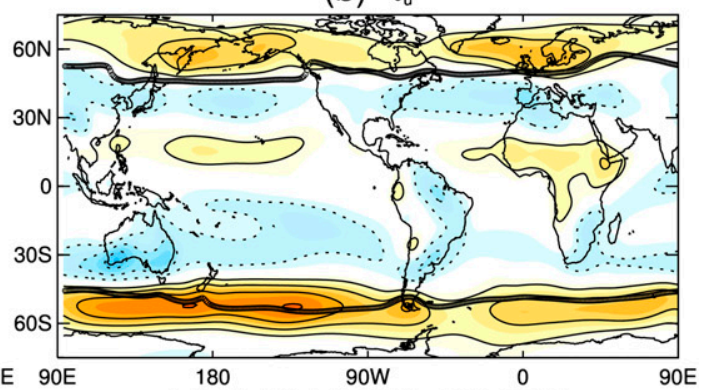

(d) STAT+LOW+CROSS

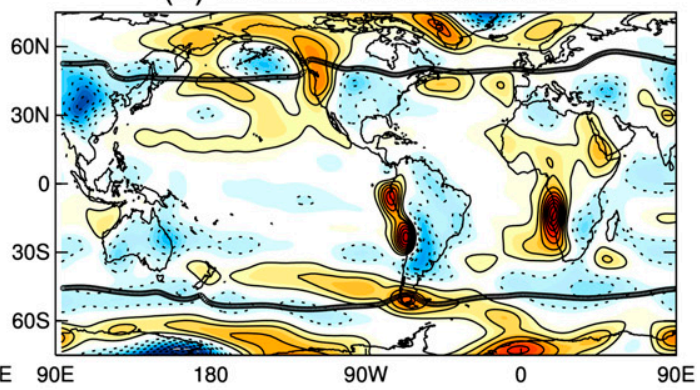

(f) Sum- $\tau_{u}$

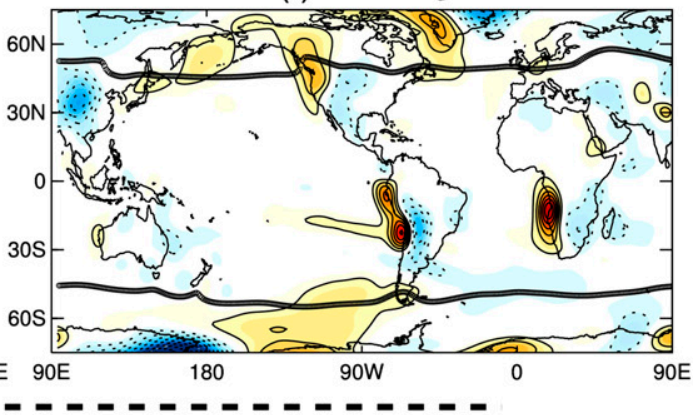

(h) LOW

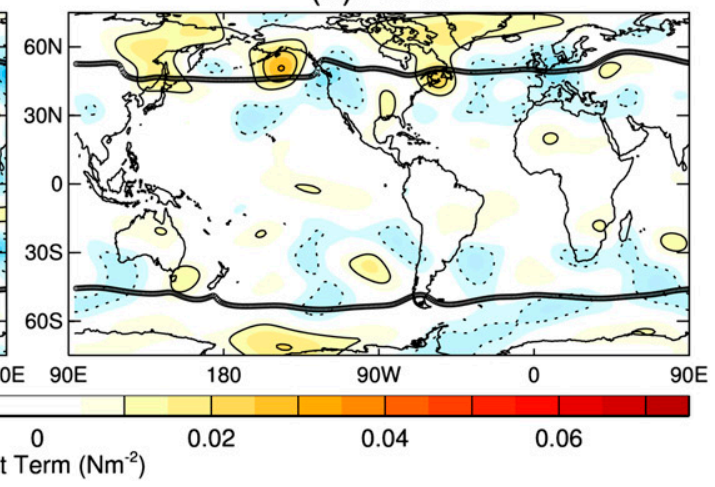

FIG. 9. As in Fig. 2, but for the future minus past difference in the SON season. The black lines denote the latitude of the maximum westerly surface wind stress for the past at each longitude.

zonal wind: 1) relatively zonally symmetric wind anomalies in the SH that, for the most part, are in the sense of a poleward shift; 2) in SON in the $\mathrm{NH}$, a poleward shift of the Atlantic and Pacific jets; 3) in JJA, a poleward shift of the Atlantic jet; 4) in DJF, a poleward shift of the Pacific jet in the west and an equatorward shift in the east; and 5) a strengthening of the Atlantic jet in the exit region and accompanying easterlies over North Africa in DJF.

To first order, the changes in $\tau_{u}$ in each season in the tropics and subtropics are maintained by changes to the 
(a) Sum all terms

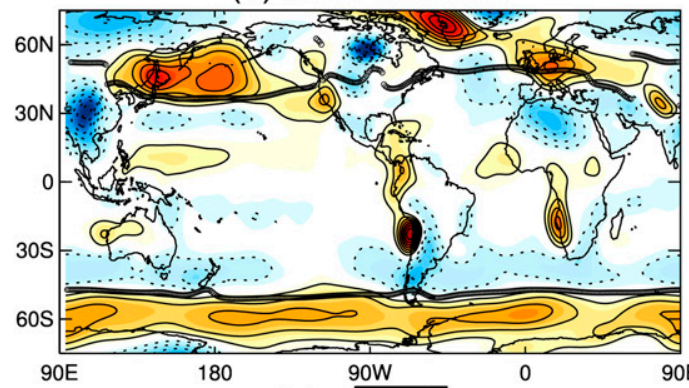

(c) $-\left(\overline{\left.U^{*} V^{*}{ }^{*}\right)_{0}}\right.$

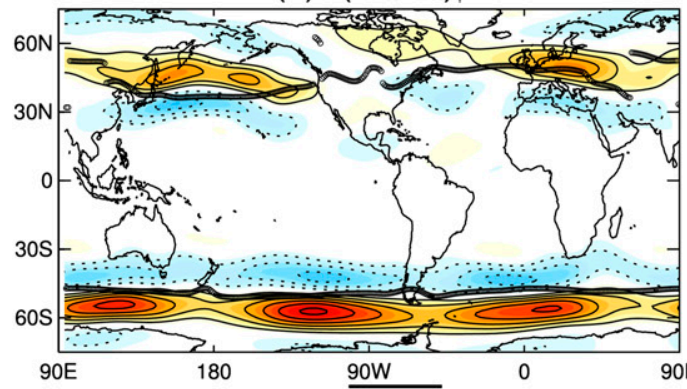

(e) $-\left(\overline{\mathrm{U}^{*}{ }_{\mathrm{H}} \mathrm{U}^{*}{ }_{\mathrm{H}}}\right)_{\lambda}$

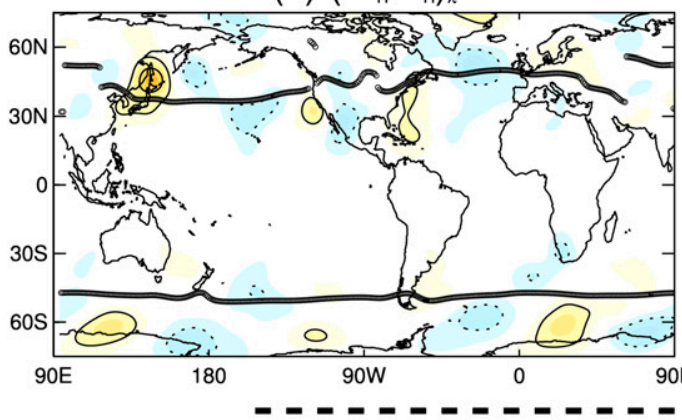

(g) STAT

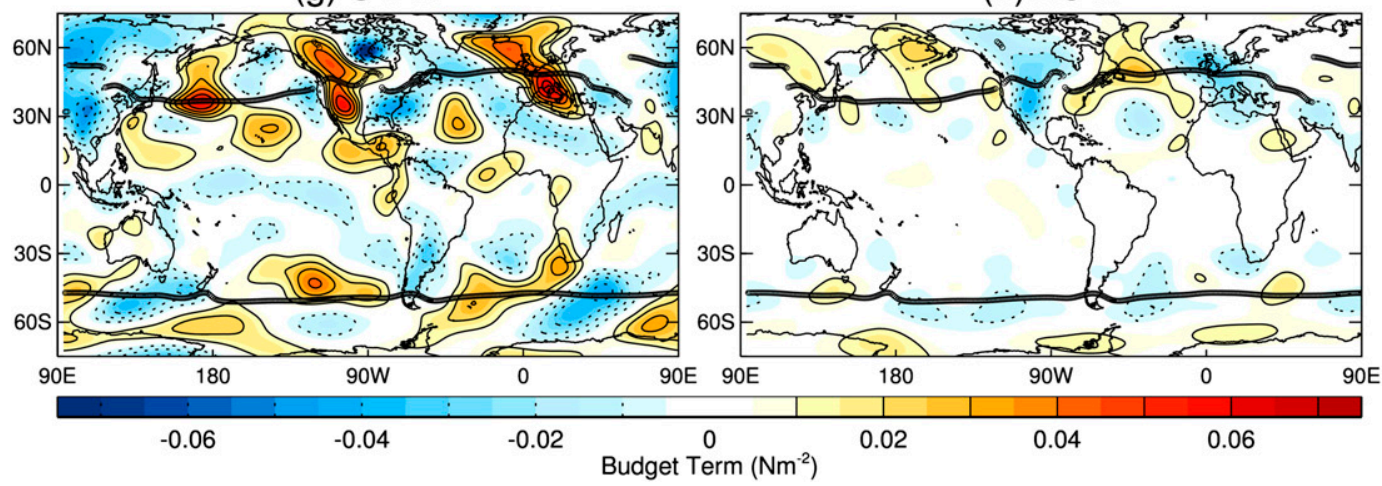

FIG. 10. As in Fig. 9, but for the DJF season. (b) $\tau$

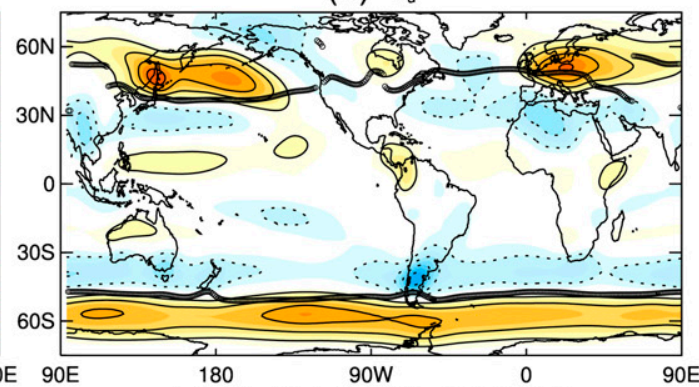

(d) STAT+LOW+CROSS

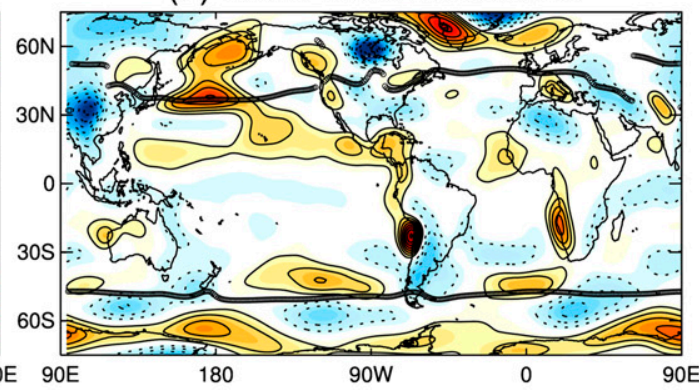

(f) Sum- $\tau_{u}$

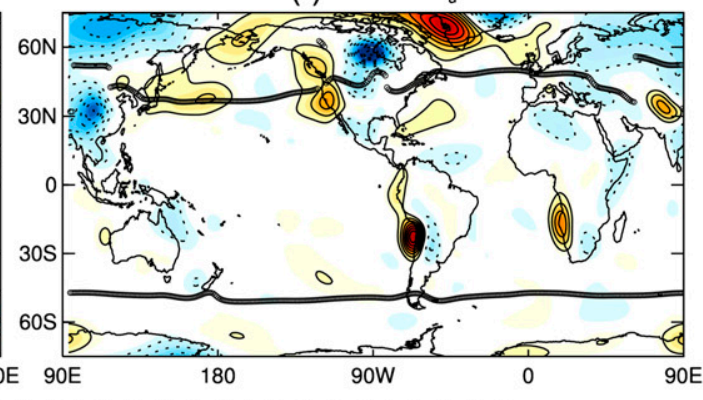

(h) LOW

only present below $700 \mathrm{hPa}$ and indicate a poleward shift of the low-level, low latitude westerly wind maximum associated with the quasi-stationary contribution. Over Asia this suggests an altered structure of the Somali jet and Indian monsoon circulation that warrants further investigation. stationary and low-frequency eddy contribution (Figs. $9 \mathrm{~d}, 10 \mathrm{~d}, 11 \mathrm{~d}$, and $12 \mathrm{~d}$ ) and the quasi-stationary component (Figs. 9g, 10g, 11g, and 12g) dominates in this. There are notable changes in the low latitudes over North Africa and Asia in the JJA season (Fig. 12b) that are not so apparent in the 700-hPa zonal wind (Fig. 7). These anomalies are 
(a) Sum all terms

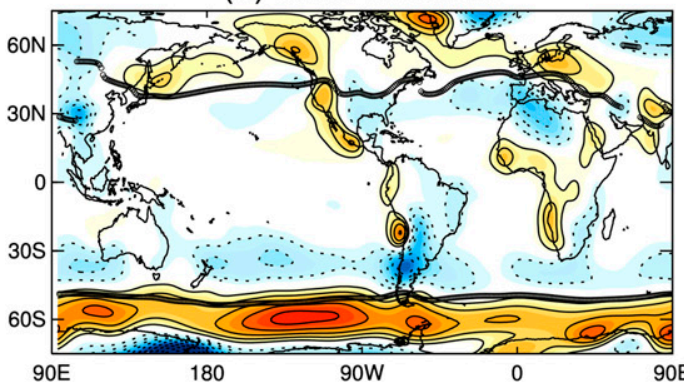

(c) $-\left(\overline{U^{*}{ }^{*} V^{*}{ }_{H}}\right)_{0}$

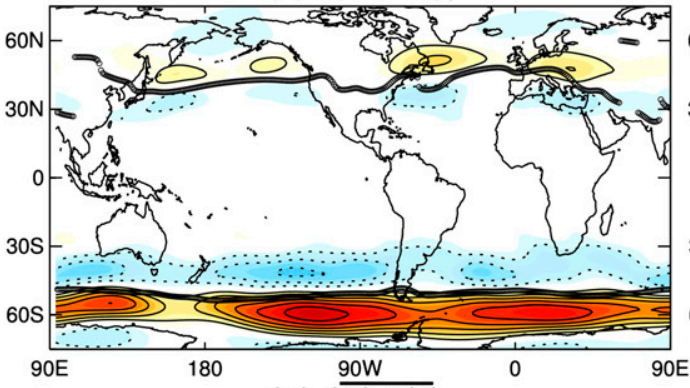

(e) $-\left(\overline{\left.u^{*}{ }^{*} u^{*}\right)_{\lambda}}\right.$

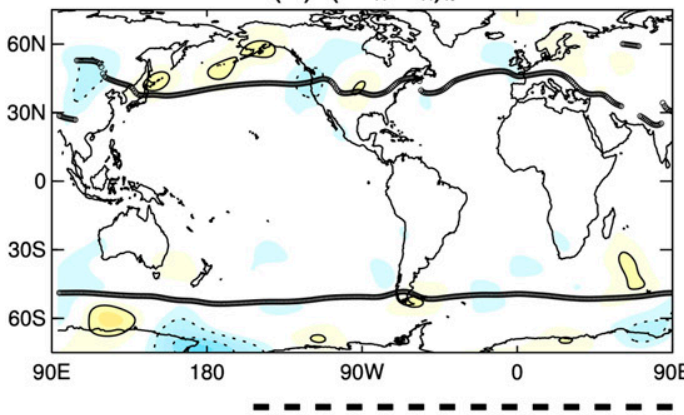

(g) STAT

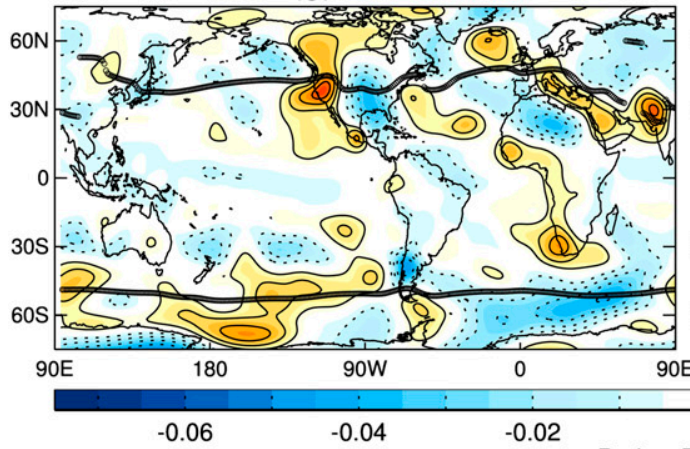

MAM

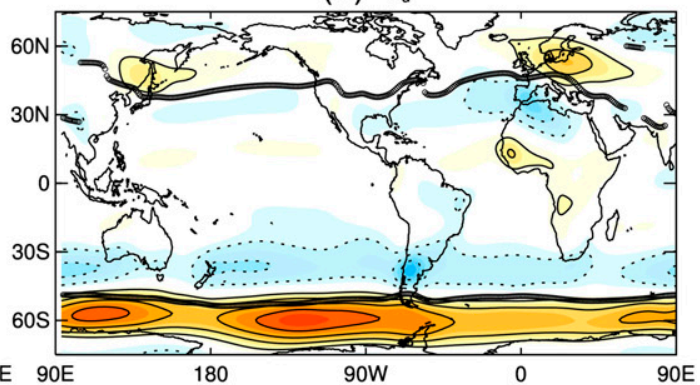

(d) STAT+LOW+CROSS

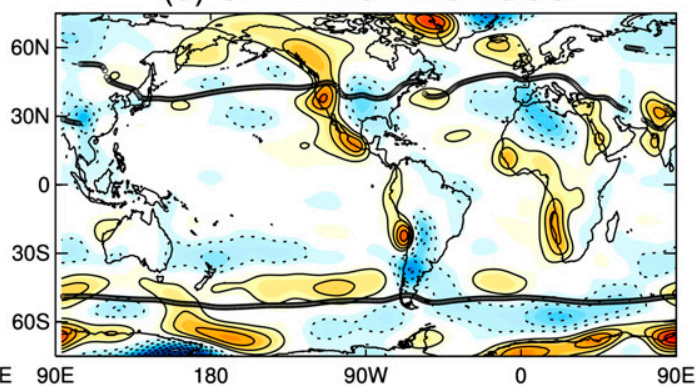

(f) Sum- $\tau_{u}$

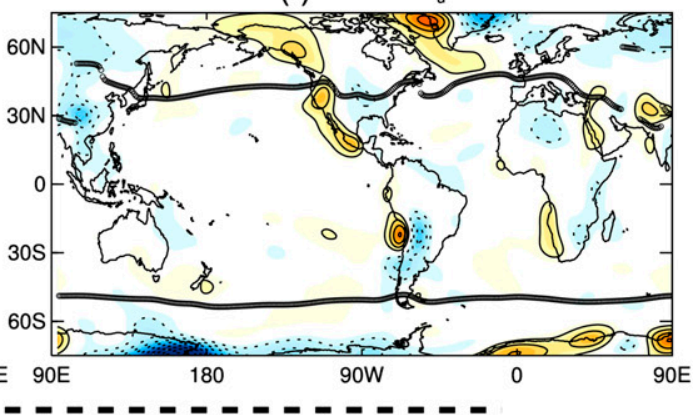

(h) LOW

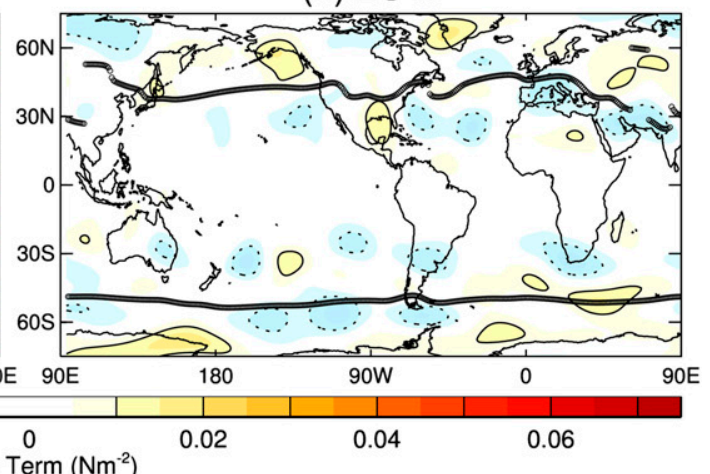

FIG. 11. As in Fig. 9, but for the MAM season.

In the midlatitudes, much like in the zonal mean, anomalous high-frequency meridional eddy momentum flux maintains the surface wind stress response locally. However, in DJF in particular, there are certain extratropical features of interest where this is not true, and changes to the low-frequency/stationary eddy terms also play an important role. The main contributions to the surface wind stress in the extratropics for each season are as follows.

- SON, Fig. 9: In the $\mathrm{SH}-\left(\overline{u_{H}^{*} v_{H}^{*}}\right)_{\phi}$ (Fig. 9c) is primarily responsible for maintaining the anomalous surface wind stress and results in a poleward shift of the jet locally, 
(a) Sum all terms

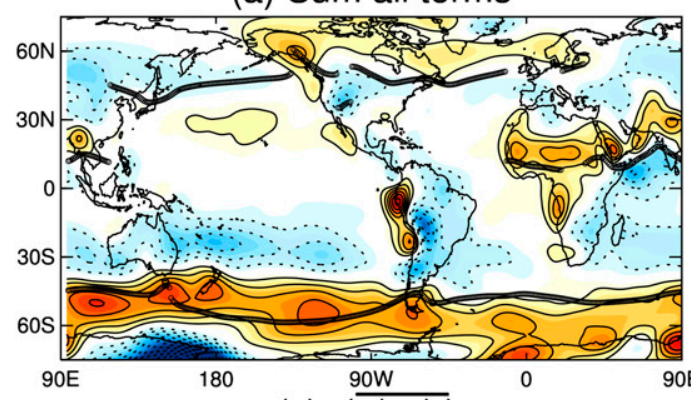

(c) $-\left(\overline{U^{*} V^{*}{ }_{H}^{*}}\right)_{\circ}$

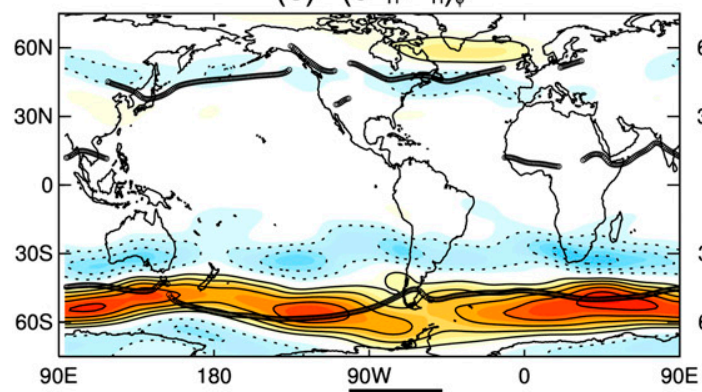

(e) $-\left(\overline{u^{*}{ }_{H} u^{*}}\right)_{\lambda}$

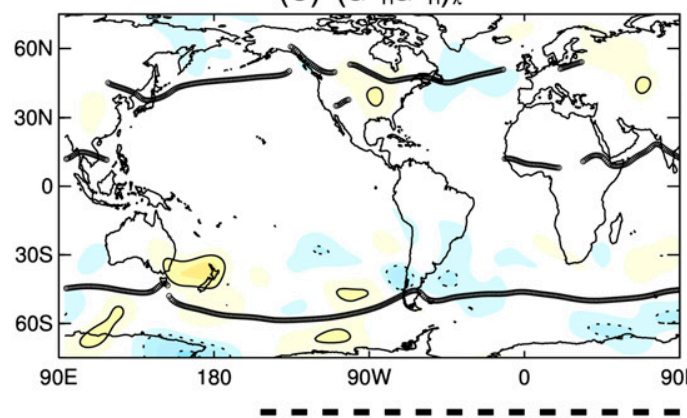

(g) STAT

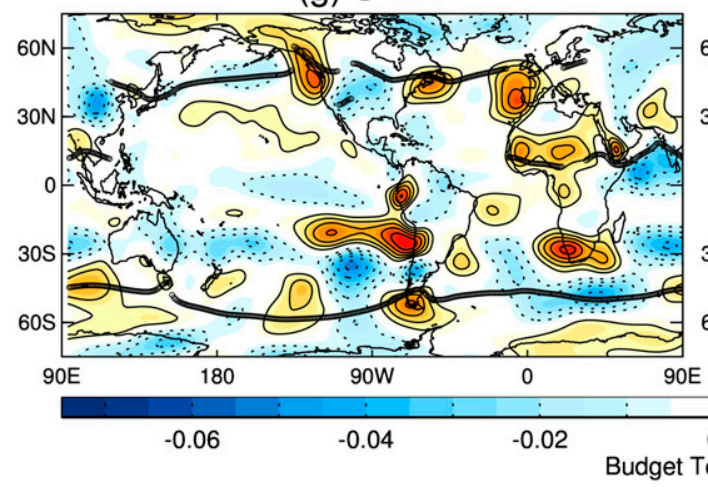

JJA

(b) $\tau_{\omega}$

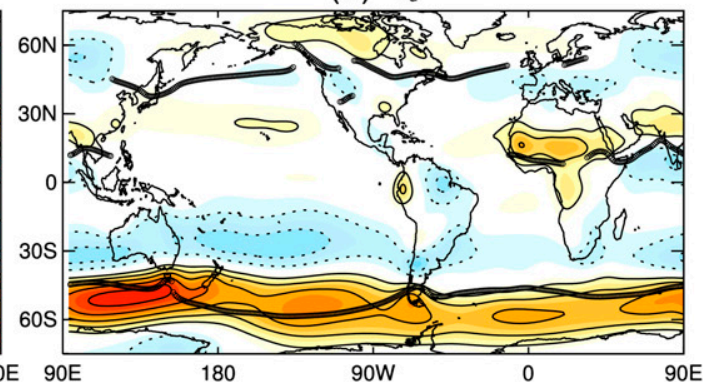

(d) STAT+LOW+CROSS

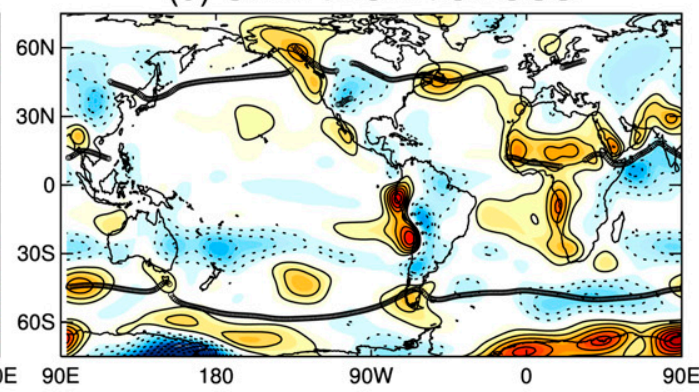

(f) Sum- $\tau_{u}$

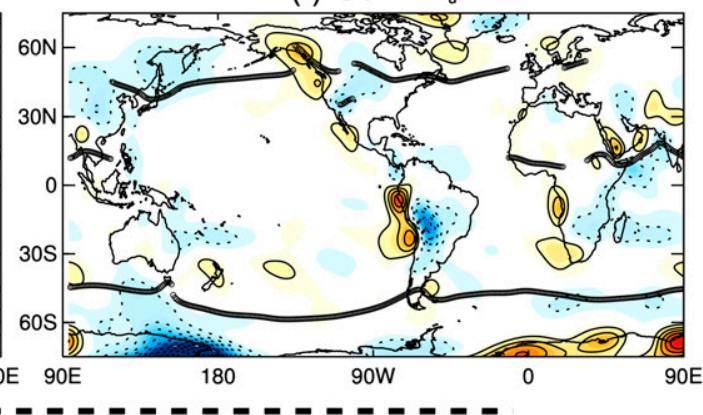

(h) LOW

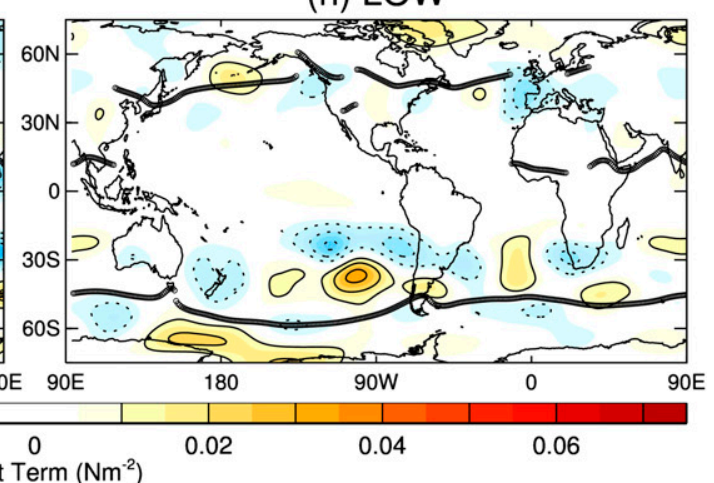

FIG. 12. As in Fig. 9, but for the JJA season.

except between around $180^{\circ}$ and $100^{\circ} \mathrm{W}$, where it acts to strengthen the jet. In the $\mathrm{NH}$, the fairly zonally symmetric shift of both the Atlantic and Pacific jets is also maintained by $-\left(\overline{u_{H}^{*} v_{H}^{*}}\right)_{\phi}$. While there are some changes to the quasi-stationary contribution in the extratropical $\mathrm{NH}$, locally the response is still dominated by the high-frequency transients, which result in a poleward shifting of the westerlies everywhere.

- DJF, Fig. 10: Again, in the SH, the zonally symmetric poleward shifting of the surface wind stress (Fig. 10b) is maintained by $-\left(\overline{u_{H}^{*} v_{H}^{*}}\right)_{\phi}$ (Fig. 10d). 
In the $\mathrm{NH}$, this season is when the most substantial zonal asymmetries in the response occur. The $-\left(\overline{u_{H}^{*} v_{H}^{*}}\right)_{\phi}$ term is important here as well, exhibiting a dipole around the climatological $\tau_{u}$ maximum and maximizing in the central and western Pacific and over Europe. This is, however, not the complete story. The large easterly anomaly over North Africa (Figs. 10b and 7a) is primarily maintained by the quasi-stationary component, as is the westerly wind stress to the north of the United Kingdom and over Scandinavia. Furthermore, over the Pacific, the quasi-stationary component contributes to the acceleration on the poleward side of the jet in the west and to the westerly anomaly to the south of the jet maximum in the central to eastern Pacific. However, in each of these regions there is also a role for the high-frequency transients. They are primarily responsible for the accelerated westerlies over the United Kingdom, France, and Germany and act to strengthen the jet in the east Pacific. So, in the east Pacific and over the Mediterranean, where the circulation anomalies do not exhibit a poleward shift, both the low-frequency/stationary waves and the high-frequency transients are necessary to explain the response. Note that there is also a tendency for the low-frequency waves to counteract the effect of the stationary waves (cf. Figs. $10 \mathrm{~g}$ and $10 \mathrm{~h})$ but the stationary component dominates to produce the features of interest.

- MAM, Fig. 11: Again, in the $\mathrm{SH},-\left(\overline{u_{H}^{*} v_{H}^{*}}\right)_{\phi}$ dominates locally in maintaining a poleward shift of $\tau_{u}$. In the $\mathrm{NH}$, there is a weak poleward shift of the surface wind stress maximum at most longitudes, maintained by $-\left(\overline{u_{H}^{*} v_{H}^{*}}\right)_{\phi}$. There is also an enhanced westerly anomaly over Europe and easterly anomaly over North Africa, similar to DJF, with the quasi-stationary eddy term primarily responsible for the easterlies over North Africa. However, it should be noted that, unlike for DJF, the 700-hPa zonal wind anomalies for the 35model mean (Fig. 7) do not exhibit this feature.

- JJA, Fig. 12: In the $\mathrm{SH}$, the $-\left(\overline{u_{H}^{*} v_{H}^{*}}\right)_{\phi}$ response is relatively zonally symmetric, despite the asymmetry of the climatological SH jet and $-\left(\overline{u_{H}^{*} v_{H}^{*}}\right)_{\phi}$, with a poleward excursion to the south and east of New Zealand. As a result, the $-\left(\overline{u_{H}^{*} v_{H}^{*}}\right)_{\phi}$ anomaly actually results in an equatorward shift of the $\tau_{u}$ maximum at these longitudes.

In the $\mathrm{NH}$, there are fairly zonally symmetric anomalies in $-\left(\overline{u_{H}^{*} v_{H}^{*}}\right)_{\phi}$. The negative is on the equatorward side of the Atlantic jet, resulting in a poleward shift but is near the center of the Pacific jet, resulting in more of a weakening.

So, in each season and hemisphere, the $\tau_{u}$ response is primarily maintained by the change in high-frequency

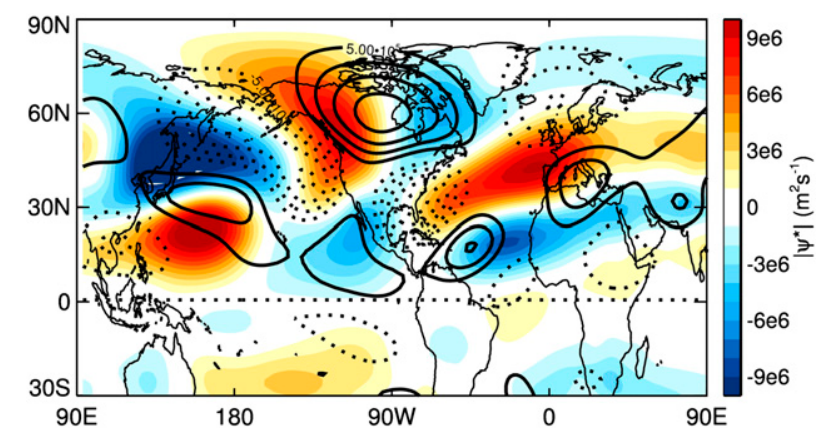

FIG. 13. DJF pressure-weighted vertically averaged eddy streamfunction for the 13 models used in the momentum budget calculation. Shading is the past climatology and contours are the future minus past difference (contour interval $=5 \times 10^{5} \mathrm{~m}^{2} \mathrm{~s}^{-1}$ ).

meridional eddy momentum fluxes locally. The exception is in the $\mathrm{NH}$ winter where there are several features that cannot be solely explained by the anomalous highfrequency transient fluxes but where the terms involving quasi-stationary eddies play an important role. These quasi-stationary eddies are in near balance, consisting, to first order, of geostrophically balanced motion. After removing this dominant balance the next dominant balance is between the $f \bar{v}_{a}$ term and the combined momentum fluxes. The surface wind stress associated with the stationary wave structures results from the unbalanced component of the flow; that is, it is associated with the small residual between these near balanced

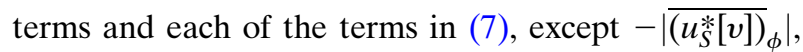
exhibit substantial anomalies. It is at this point where a further decomposition of the budget terms is limited in its usefulness. What we can conclude from the stationary terms is that the climatological planetary wave structures are changing. Associated with this change is a change in the terms that are in near balance as well as a change in the imbalanced component that maintains the surface wind stress. The anomalous stationary circulation patterns of importance in the DJF season are shown in Fig. 13, which shows the pressure-weighted, vertically averaged streamfunction. The easterly anomalies over North Africa and westerly anomalies in the jet exit region over Europe are associated with flow around a barotropic anticyclonic anomaly centered over the Mediterranean, whereas the equatorward shift of the jet in the east Pacific is associated with a barotropic cyclonic circulation anomaly off the western coast of North America. Comparison with the climatological streamfunction does not reveal a simple relationship between the anomaly and the climatology; for instance, it is not a simple strengthening, weakening, or shift of the climatological stationary waves. The budget analysis has revealed that these changes in climatological stationary wave structure are an important contribution to the change in the midlatitude westerlies in 
the DJF season, resulting in localized features that do not resemble a poleward shift. Future work will focus on understanding how these stationary wave anomalies are produced.

\section{Discussion}

The primary aim of this analysis was to go beyond zonal- or basin-mean analyses and assess where and when a poleward shifting of the midlatitude westerlies actually occurs and further to assess the contributions to these responses from a momentum budget perspective. In the SH, in DJF and MAM, there is a high-frequency eddy-driven poleward shift of the midlatitude westerlies locally at each longitude. This is also the case in JJA and SON, with the exception of a region south and east of New Zealand, where the climatological jet is placed farther poleward and the rather zonally symmetric (in terms of latitudinal location $)-\left(\overline{u_{H}^{*} v_{H}^{*}}\right)_{\phi}$ anomaly actually results in an equatorward shift.

In the $\mathrm{NH}$, while the zonal-mean jet shifts poleward in each season, this represents an average over considerable zonal asymmetry and seasonal variation. The one season that exhibits a robust poleward shift of both the Atlantic and Pacific jets with a strong model consensus is SON, which is also the season where the zonal-mean response maximizes (see also Gillett and Fyfe 2013; Barnes and Polvani 2013). The multimodel mean also exhibits a poleward shift of each jet in MAM, although the zonal wind anomalies are weaker and there is less of a model consensus. In JJA, the Atlantic jet shifts poleward with a reasonable model consensus but this does not happen in the Pacific. Instead, the jet weakens and, if anything, shifts equatorward in July. Barnes and Polvani (2013) performed a basin-mean analysis of jet shifts and found a very weak, statistically insignificant poleward shift of the Pacific jet in this season. Here, we have used a different number of models and calculated the shift at each longitude rather than in the basin mean, which may account for this difference. Each of the above anomalies in surface wind stress is maintained by anomalous high-frequency meridional eddy momentum flux convergence. In terms of the mechanisms involved in this high-frequency transient response, it seems that the seasonality should provide some clues. In particular, why is it during the fall months that the largest change in $-\left(\overline{u_{H}^{*} v_{H}^{*}}\right)_{\phi}$ and the most robust poleward shifting of the $\mathrm{NH}$ westerlies occur?

One could argue that the DJF season in the NH is perhaps the most important season for understanding and predicting future changes in the midlatitude westerlies. It is when the midlatitude jets are strongest, storm activity is greatest, and semiarid regions vulnerable to climate change, such as southwestern North America and the Mediterranean, receive their moisture. While the zonal-mean jet shifts poleward in this season, locally, the only region where this is the case is the western Pacific. On the eastern side of the Pacific basin the jet actually shifts equatorward. In the Atlantic, there is little consensus on the sign of the response over much of the basin, but there is a clear signal of a strengthened Atlantic jet in the jet exit region and anomalous easterly winds over North Africa. It is in the DJF season, in the $\mathrm{NH}$, where the momentum budget yields the most interesting results. While there is clearly also a dominant role for the high-frequency meridional eddy momentum flux in maintaining the anomalous surface wind stress locally, it cannot completely explain the anomalies over the Pacific basin or the anomalous easterlies over North Africa and a component of the anomalous westerlies over Europe. In these regions, the quasi-stationary eddy contribution is also important.

The circulation anomalies in the east Pacific and Mediterranean are of particular importance for future hydroclimate changes. California is a region of large uncertainty, lying between the moistening midlatitudes and the drying subtropics. Neelin et al. (2013) showed that the CMIP5 models exhibit more of a consensus on future precipitation in this region than previous multimodel intercomparisons and suggest an enhanced precipitation over California, in association with this equatorward shifting of the eastern Pacific jet. Seager et al. (2014b, manuscript submitted to J. Climate) have demonstrated that this is primarily due to enhanced moisture flux convergence by the mean flow. Seager et al. (2014a) demonstrated that the Mediterranean will undergo substantial drying in the future, mostly because of an enhanced moisture flux divergence by the mean flow that is related to the anomalous high pressure/ anticyclonic circulation set up over the Mediterranean basin. The enhanced westerlies over Europe and easterlies over North Africa are part of this anticyclonic circulation. Therefore, the predictions of future moisture budget changes in vulnerable regions of the globe are strongly related to the predictions of the midlatitude circulation in these regions and it is important that they be understood.

The present results based on the vertically integrated momentum budget suggest that both the anomalies on the eastern side of the Pacific basin and over the Mediterranean in DJF are not solely explained by anomalous high-frequency meridional eddy momentum flux convergence, but require additional interpretation through changes in the stationary wave field in particular. There have been a number of studies that have examined stationary wave changes under increasing greenhouse 
gases either in individual models (Stephenson and Held 1993; Joseph et al. 2004; Wang and Kushner 2011) or in previous multimodel intercomparisons (Brandefelt and Körnich 2008; Freitas and Rao 2013). Among these studies there is some disagreement as to the structure of the stationary wave response and, for example, the relative importance of changes in the mean flow versus changes in the diabatic forcing for producing the response. However, the features of interest here-namely, the cyclonic circulation to the west of North America and the anticyclonic circulation centered over the Mediterranean-are in agreement with the structures exhibited by the majority of models in the study of Brandefelt and Körnich (2008) and the model examined by Wang and Kushner (2011) and therefore seem to be emerging as the consensus stationary wave response to increasing greenhouse gases. Here, we have demonstrated that this response plays an important role in determining the latitudinal shift of the westerlies locally despite the tendency of the high-frequency transients to shift the circulation poleward. There are a number of possible changes that may be contributing to this such as altered flow over topography, changing land-sea temperature contrasts, altered tropospheric static stability, altered generation of Rossby waves from the tropics, or altered mean flow changing the propagation of such waves. Brandefelt and Körnich (2008) and Wang and Kushner (2011) have demonstrated an important role for changes in the zonal-mean flow in producing the Pacific stationary wave response although they disagree as to the role of changes in the mean flow for the Mediterranean anomaly. Quite how the anomalous zonalmean flow exerts its influence and the additional roles for changes in diabatic heating and transients remain to be understood. Each of the above mechanisms may be important in different regions and future work will focus on understanding which is most relevant.

Clearly, as already well-established in the literature, there is also an important role for changes in the highfrequency meridional eddy momentum flux in all seasons at virtually all longitudes and work remains to decipher the relative importance of each of the mechanisms discussed in the introduction. It is quite surprising that despite all the zonal asymmetry in the climatological jets, and in the response, the anomalous high-frequency momentum flux is rather zonally symmetric. This suggests that the change in the eddies is triggered by a process that is zonally symmetric (e.g., lower-stratospheric cooling/ tropical upper-tropospheric warming) and is not strongly influenced by zonal asymmetries in the jet stream. It should also be noted that, over Europe in particular, there are substantial model biases in the climatological highfrequency transient momentum fluxes (see appendix) that may introduce some uncertainty in the response there. Future work should aim to understand this bias and its implications.

\section{Conclusions}

The seasonal and zonal variations in the midlatitude response to climate change and the accompanying vertically integrated momentum budgets have been analyzed in the CMIP5 models. This was motivated by the desire to document and understand the midlatitude circulation changes both in the zonal mean and on a more regional scale. While it is not possible to unambiguously draw conclusions in terms of causality from a budget analysis like this, it can at least direct the future search for mechanisms, which may make use of more idealized model setups.

As already well established, there is a poleward shift of the zonal-mean jet in each season and hemisphere. This has been discussed in many studies prior to this one (Yin 2005; Fyfe and Saenko 2006; Kidston and Gerber 2010; Swart and Fyfe 2012; Wilcox et al. 2012; Barnes and Polvani 2013; Bracegirdle et al. 2013) and here the important role of high-frequency (less than 10 days) meridional eddy momentum flux in maintaining this response is demonstrated in the CMIP5 archive.

Perhaps less well established are the zonal and seasonal variations in the midlatitude circulation response. While the SH circulation response can be described, to a large extent, as a poleward shifting of the midlatitude westerlies locally at each longitude, this is not universally true in the NH. There are various regions and seasons where the circulation changes do not fit the typical interpretation of a poleward shift of the circulation. This is particularly true in the $\mathrm{NH}$ winter seasons where there is an equatorward shift of the jet in the east Pacific and strengthening of the Atlantic jet over Europe and easterly anomalies farther south over North Africa. An important contribution to these anomalies comes from changes in the low-frequency/stationary waves and, in particular, the stationary component of that. The mechanism(s) by which the climatological stationary waves change is not well understood and, since this is of great importance for regional climate change, future work will aim to remedy this. An improved understanding of these aspects of future climate change will increase our confidence that GCMs are resolving and simulating the important processes correctly and that we can have faith in their future predictions of the midlatitude circulation and associated regional hydroclimate.

Acknowledgments. We are grateful to Haibo Liu and Naomi Henderson for downloading the monthly mean 
(a) Budget, 1979-2005

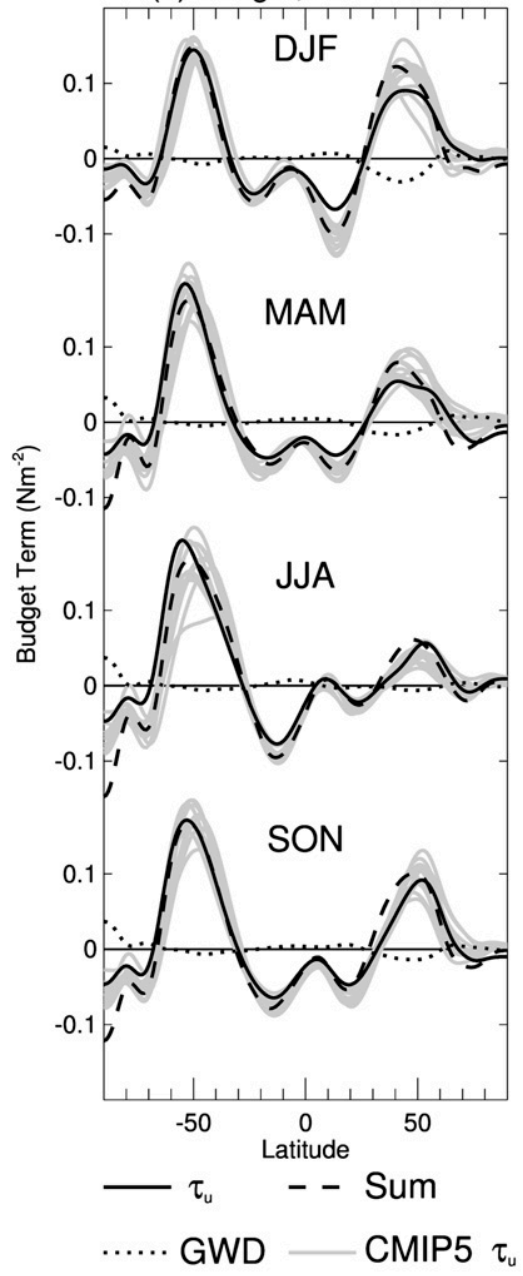

(b) Budget decomposition

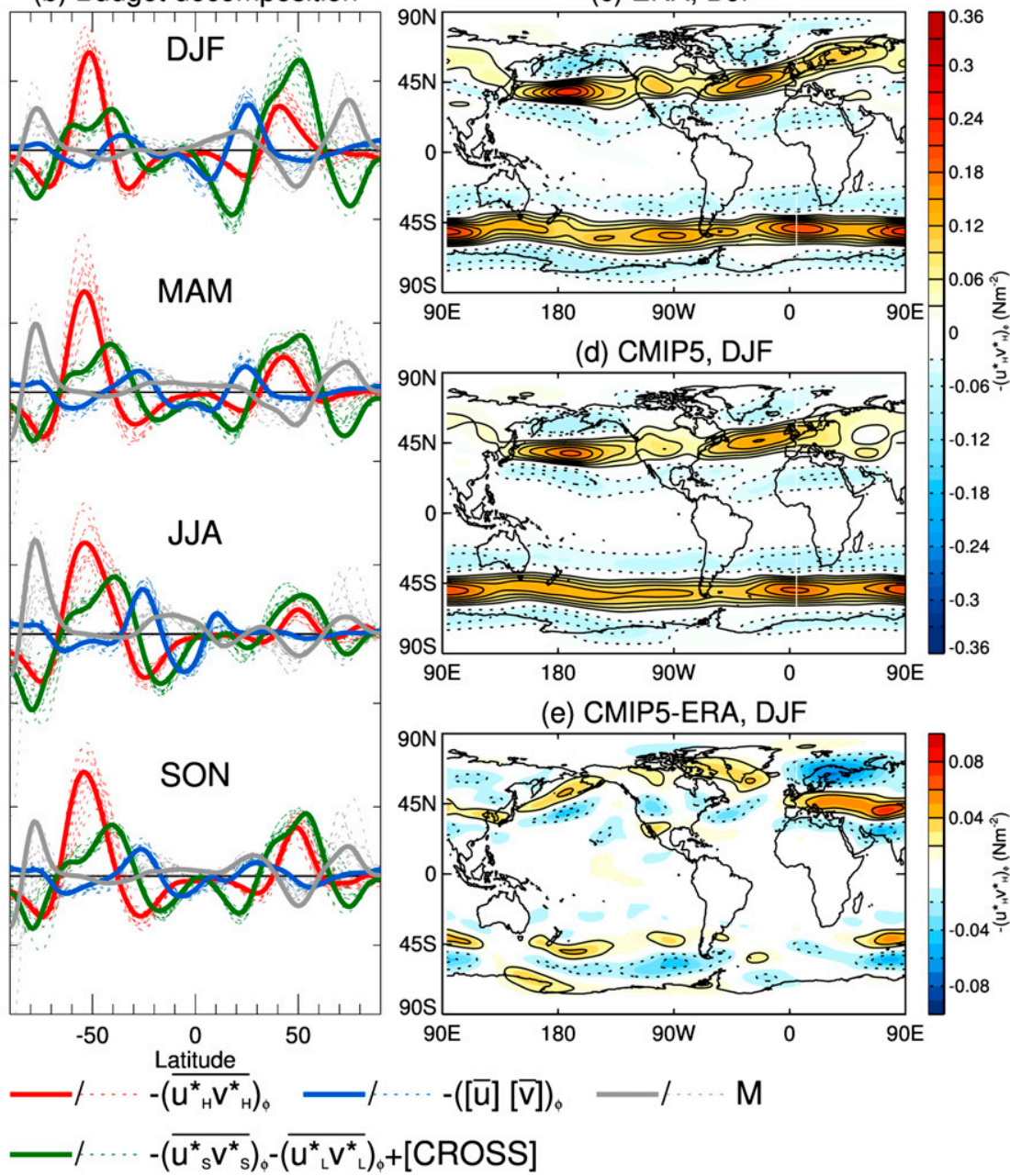

FIG. A1. (a) A comparison of the ERA-Interim zonal-mean momentum budget with that of CMIP5 for (top to bottom) each season. The ERA-Interim $\tau_{u}$ (solid black); the ERA-Interim sum of terms, excluding the gravity wave drag contribution (dashed black); the ERAInterim gravity wave drag contribution (black dotted); and $\tau_{u}$ for each of the CMIP5 models (gray). (b) The contributions to the momentum budget for (top to bottom) each season as in Fig. 1b, but for ERA-Interim (thick solid) and each of the CMIP5 models individually (thin dashed). (c)-(e) The contribution from vertically integrated high-frequency meridional eddy momentum flux in DJF for ERA-Interim, CMIP5 multimodel mean, and the difference between CMIP5 and ERA-Interim, respectively.

and daily data used in this study. IRS was funded by a Lamont-Doherty Earth Observatory postdoctoral fellowship and NSF Award AGS-1317469. RS was supported by NOAA Award NA10OAR4310137 (Global Decadal Hydroclimate Variability and Change) and DOE Award DE-SC0005107. TAS acknowledges support from the NSF Grant AGS-1255208 and from the David and Lucile Packard Foundation. We acknowledge the World Climate Research Programme's Working Group on Coupled Modelling, which is responsible for CMIP, and we thank the climate modeling groups (listed in Table 1 of this paper) for producing and making available their model output. For CMIP the U.S. Department of Energy's Program for Climate Model
Diagnosis and Intercomparison provides coordinating support and led development of software infrastructure in partnership with the Global Organization for Earth System Science Portals. We also thank two anonymous reviewers for their helpful comments.

\section{APPENDIX}

\section{A Comparison with ERA-Interim}

Here, the historical CMIP5 budgets are compared with that of ERA-Interim (Dee et al. 2011). The ERAInterim budget was calculated using 6-hourly data on the same pressure levels as for CMIP5 from 1979 to 2005 
(i.e., the same period as considered the "past" for CMIP5). The full 2D vertically integrated budget could not be closed satisfactorily for ERA-Interim. It relies on exact computation of a small residual between large terms and, for reasons unknown, the quasi-stationary contribution could not be calculated accurately enough. Note that this was also true of a number of the CMIP5 models. Nevertheless, we can compare the zonal-mean budget, which closes well, and the high-frequency meridional momentum flux climatology.

Beginning with the zonal mean, Fig. A1a compares the sum of terms and $\tau_{u}$ for ERA-Interim (black solid and dashed) with $\tau_{u}$ for each CMIP5 model (gray lines). Furthermore, ERA-Interim provides the vertically integrated contribution from orographic gravity wave drag. This is not included in the sum but shown by the black dashed line. The CMIP5 models (Fig. 1a) exhibit a residual in the zonal-mean budget in the NH midlatitudes, particularly during winter. This is also true for ERA-Interim when the gravity wave drag contribution is not included and Fig. A1a demonstrates that this residual is largely accounted for by the neglect of the gravity wave drag contribution.

Another important point to note from Fig. A1a is a substantial bias in the $\mathrm{NH}$ subtropical easterly $\tau_{u}$, particularly during winter, in the CMIP5 models. The easterly $\tau_{u}$ is actually almost twice as large in each of the CMIP5 models as it is in ERA-Interim. However, in ERA-Interim each of the individual contributions to the budget actually compare very well with those in CMIP5 (Fig. A1b) and actually sum up to a similar total (black dashed in Fig. A1a). The reduced subtropical easterly $\tau_{u}$ in ERA-Interim cannot be explained by a bias in any of the calculated terms, which suggests that is it being introduced by the assimilation tendencies. The cause of this bias warrants further investigation.

Finally, Figs. A1c-e compare the $-\left(\overline{u_{H}^{*} v_{H}^{*}}\right)_{\phi}$ contribution for ERA-Interim with that of CMIP5 for the DJF season. In the $\mathrm{SH}$, there is an equatorward bias in $-\left(\overline{u_{H}^{*} v_{H}^{*}}\right)_{\phi}$ associated with the common equatorward bias in the SH jet in the models. However, the largest bias in this term actually occurs in the $\mathrm{NH}$ over Europe. It is well known that the Atlantic jet in models tends to be too zonal (Woollings 2010) and it is clear that associated with this there is substantial bias in the structure of the $-\left(\overline{u_{H}^{*} v_{H}^{*}}\right)_{\phi}$ term. In ERA-Interim the westerly tendency due to $-\left(\overline{u_{H}^{*} v_{H}^{*}}\right)_{\phi}$ is considerably more tilted in the Atlantic with much larger momentum flux convergence over northern Europe and Russia. This bias is of concern since, under climate change, $-\left(\overline{u_{H}^{*} v_{H}^{*}}\right)_{\phi}$ has a tendency to shift poleward. For example, Fig. 10c demonstrates a poleward shift of the climatological maximum in $-\left(\overline{u_{H}^{*} v_{H}^{*}}\right)_{\phi}$ over Europe in DJF. Given that the models do not get the climatological maximum in $-\left(\overline{u_{H}^{*} v_{H}^{*}}\right)_{\phi}$ in the correct place, there may be considerable uncertainty in this response and associated circulation changes because of this model bias.

\section{REFERENCES}

Arblaster, J. M., and G. A. Meehl, 2006: Contributions of external forcings to southern annular mode trends. J. Climate, 19, 28962905, doi:10.1175/JCLI3774.1.

Bals-Elsholz, T. M., E. H. Atallah, L. F. Bosart, T. A. Wasula, M. J. Cempa, and A. R. Lupo, 2001: The wintertime southern hemisphere split jet: Structure, variability, and evolution. J. Climate, 14, 4191-4215, doi:10.1175/1520-0442(2001)014<4191: TWSHSJ $>2.0 . \mathrm{CO} ; 2$.

Barnes, E. A., and L. M. Polvani, 2013: Response of the midlatitude jets and of their variability to increased greenhouse gases in the CMIP5 models. J. Climate, 26, 7117-7135, doi:10.1175/ JCLI-D-12-00536.1.

Blackmon, M. L., Y. H. Lee, and J. M. Wallace, 1984: Horizontal structure of $500 \mathrm{mb}$ height fluctuations with long, intermediate and short time scales. J. Atmos. Sci., 41, 961-979, doi:10.1175/ 1520-0469(1984)041<0961:HSOMHF>2.0.CO;2.

Bracegirdle, T. J., E. Shuckburgh, J.-B. Sallee, Z. Wang, A. J. S. Meijers, N. Bruneau, T. Phillips, and L. J. Wilcox, 2013: Assessment of surface winds over the Atlantic, Indian, and $\mathrm{Pa}-$ cific Ocean sectors of the Southern Ocean in CMIP5 models: Historical bias, forcing response, and state dependence. J. Geophys. Res., 118, 547-562, doi:10.1002/jgrd.50153.

Brandefelt, J., and H. Körnich, 2008: Northern Hemisphere stationary waves in future climate projections. J. Climate, 21, 6341-6353, doi:10.1175/2008JCLI2373.1.

Brayshaw, D. J., B. Hoskins, and M. Blackburn, 2009: The basic ingredients of the North Atlantic storm track. Part I: Land-sea contrast and orography. J. Atmos. Sci., 66, 2539-2558, doi:10.1175/2009JAS3078.1.

,-- , and -2011 : The basic ingredients of the North Atlantic storm track. Part II: Sea surface temperatures. J. Atmos. Sci., 68, 1784-1805, doi:10.1175/2011JAS3674.1.

Butler, A. H., D. W. J. Thompson, and R. Heikes, 2010: The steadystate atmospheric circulation response to climate change-like thermal forcings in a simple general circulation model. $\mathrm{J}$. Climate, 23, 3474-3496, doi:10.1175/2010JCLI3228.1.

Catto, J. L., L. C. Shaffrey, and K. I. Hodges, 2011: Northern Hemisphere extratropical cyclones in a warming climate in the HiGEM high-resolution climate model. J. Climate, 24, 53365351, doi:10.1175/2011JCLI4181.1.

Chang, E. K. M., Y. Guo, and X. Xia, 2012: CMIP5 multimodel ensemble projection of storm track change under global warming. J. Geophys. Res., 117, D23118, doi:10.1029/ 2012JD018578.

Chen, G., J. Lu, and D. M. W. Frierson, 2008: Phase speed spectra and the latitude of surface westerlies: Interannual variability and global warming trend. J. Climate, 21, 5942-5959, doi:10.1175/ 2008JCLI2306.1.

,-- , and L. Sun, 2013: Delineating the eddy-zonal flow interaction in the atmospheric circulation response to climate forcing: Uniform SST warming in an idealized aquaplanet model. J. Atmos. Sci., 70, 2214-2233, doi:10.1175/ JAS-D-12-0248.1.

Dee, D. P., and Coauthors, 2011: The ERA-Interim reanalysis: Configuration and performance of the data assimilation 
system. Quart. J. Roy. Meteor. Soc., 137, 553-597, doi:10.1002/ qj.828.

Dima, I. M., J. M. Wallace, and I. Kraucunas, 2005: Tropical zonal momentum balance in the NCEP reanalyses. J. Atmos. Sci., 62, 2499-2513, doi:10.1175/JAS3486.1.

Duchon, C. E., 1979: Lanczos filtering in one and two dimensions. J. Appl. Meteor., 18, 1016-1022, doi:10.1175/ 1520-0450(1979)018<1016:LFIOAT > 2.0.CO;2.

Freitas, A. C. V., and V. B. Rao, 2013: Global changes in propagation of stationary waves in a warming scenario. Quart. J. Roy. Meteor. Soc., 140, 364-383, doi:10.1002/qj.2151.

Fyfe, J. C., and O. A. Saenko, 2006: Simulated changes in the extratropical Southern Hemisphere winds and currents. Geophys. Res. Lett., 33, L06701, doi:10.1029/2005GL025332.

Gillett, N. P., and J. C. Fyfe, 2013: Annular mode changes in the CMIP5 simulations. Geophys. Res. Lett., 40, 1189-1193, doi:10.1002/grl.50249.

Harvey, B. J., L. C. Shaffrey, T. J. Woollings, G. Zappa, and K. I. Hodges, 2012: How large are projected 21st century storm track changes? Geophys. Res. Lett., 39, L18707, doi:10.1029/ 2012 GL052873.

Held, I. M., and B. J. Soden, 2006: Robust responses of the hydrological cycle to global warming. J. Climate, 19, 5686-5699, doi:10.1175/JCLI3990.1.

_- M. Ting, and H. Wang, 2002: Northern winter stationary waves: Theory and modeling. J. Climate, 15, 2125-2144, doi:10.1175/1520-0442(2002)015<2125:NWSWTA > 2.0.CO;2.

Hoskins, B. J., and D. J. Karoly, 1981: The steady linear response of a spherical atmosphere to thermal and orographic forcing. J. Atmos. Sci., 38, 1179-1196, doi:10.1175/ 1520-0469(1981)038<1179:TSLROA > 2.0.CO;2.

— Hemisphere storm tracks. J. Climate, 18, 4108-4129, doi:10.1175/ JCLI3570.1.

_ I. N. James, and G. H. White, 1983: The shape, propagation and mean-flow interaction of large-scale weather systems. J. Atmos. Sci., 40, 1595-1612, doi:10.1175/1520-0469(1983)040<1595: TSPAMF $>2.0 . \mathrm{CO} ; 2$.

Inatsu, M., and B. J. Hoskins, 2004: The zonal asymmetry of the Southern Hemisphere winter storm track. J. Climate, 17, 48824892, doi:10.1175/JCLI-3232.1.

Joseph, R., M. Ting, and P. J. Kushner, 2004: The global stationary wave response to climate change in a coupled GCM. J. Climate, 17, 540-556, doi:10.1175/1520-0442(2004)017<0540: TGSWRT $>2.0 . \mathrm{CO} ; 2$.

Kaspi, Y., and T. Schneider, 2013: The role of stationary eddies in shaping midlatitude storm tracks. J. Atmos. Sci., 70, 25962613, doi:10.1175/JAS-D-12-082.1.

Kidston, J., and E. P. Gerber, 2010: Intermodel variability of the poleward shift of the austral jet stream in the CMIP3 integrations linked to biases in 20th century climatology. Geophys. Res. Lett., 37, L09708, doi:10.1029/2010GL042873.

— S. M. Dean, J. A. Renwick, and G. K. Vallis, 2010: A robust increase in the eddy length scale in the simulation of future climates. Geophys. Res. Lett., 37, L03806, doi:10.1029/2009GL041615.

_- G. K. Vallis, S. M. Dean, and J. A. Renwick, 2011: Can the increase in the eddy length scale under global warming cause the poleward shift of the jet streams? J. Climate, 24, 37643780, doi:10.1175/2010JCLI3738.1.

Lorenz, D. J., and E. T. DeWeaver, 2007: Tropopause height and zonal wind response to global warming in the IPCC scenario integrations. J. Geophys. Res., 112, D10119, doi:10.1029/ 2006JD008087.
Lu, J., G. Chen, and D. M. W. Frierson, 2008: Response of the zonal-mean atmospheric circulation to El Niño versus global warming. J. Climate, 21, 5835-5851, doi:10.1175/ 2008JCLI2200.1.

McLandress, C., T. G. Shepherd, J. F. Scinocca, D. A. Plummer, M. Sigmond, A. I. Jonsson, and M. C. Reader, 2011: Separating the dynamical effects of climate change and ozone depletion. Part II: Southern Hemisphere troposphere. J. Climate, 24, 1850-1868, doi:10.1175/2010JCLI3958.1.

Miller, R. L., G. A. Schmidt, and D. T. Shindell, 2006: Forced annular variations in the 20th century Intergovernmental Panel on Climate Change Fourth Assessment Report Models. J. Geophys. Res., 111, D18101, doi:10.1029/2005JD006323.

Morgenstern, O., and Coauthors, 2010: Anthropogenic forcing of the Northern Annular Mode in CCMVal-2 models. J. Geophys. Res., 115, D00M03, doi:10.1029/2009JD013347.

Neelin, J. D., B. Langenbrunner, J. E. Meyerson, A. Hall, and N. Berg, 2013: California winter precipitation change under global warming in the Coupled Model Intercomparison Project 5 ensemble. J. Climate, 26, 6238-6256, doi:10.1175/ JCLI-D-12-00514.1.

Plumb, R. A., 1986: Three-dimensional propagation of transient quasi-geostrophic eddies and its relationship with the eddy forcing of the time-mean flow. J. Atmos. Sci., 43, 1657-1678, doi:10.1175/1520-0469(1986)043<1657:TDPOTQ>2.0.CO;2.

Polvani, L. M., D. W. Waugh, J. P. Correa, and S. W. Son, 2011: Stratospheric ozone depletion: The main driver of twentieth-century atmospheric circulation changes in the Southern Hemisphere. J. Climate, 24, 795-812, doi:10.1175/ 2010JCLI3772.1.

Previdi, M., and B. G. Liepert, 2007: Annular modes and Hadley cell expansion under global warming. Geophys. Res. Lett., 34, L22701, doi:10.1029/2007GL031243.

Randel, W. J., and I. M. Held, 1991: Phase speed spectra of transient eddy fluxes and critical layer absorption. J. Atmos. Sci., 48, 688-697, doi:10.1175/1520-0469(1991)048<0688: PSSOTE $>2.0 . \mathrm{CO} ; 2$.

Riviere, G., 2011: A dynamical interpretation of the poleward shift of the jet streams in global warming scenarios. J. Atmos. Sci., 68, 1253-1272, doi:10.1175/2011JAS3641.1.

Sardeshmukh, P. D., and B. J. Hoskins, 1984: Spatial smoothing on the sphere. Mon. Wea. Rev., 112, 2524-2529, doi:10.1175/ 1520-0493(1984)112<2524:SSOTS > 2.0.CO;2.

Schneider, E. K., and I. G. Watterson, 1984: Stationary Rossby wave propagation through easterly layers. J. Atmos. Sci., 41, 2069-2083, doi:10.1175/1520-0469(1984)041<2069: SRWPTE $>2.0 . \mathrm{CO} ; 2$.

Schneider, T., 2006: The general circulation of the atmosphere. Annu. Rev. Earth Planet. Sci., 34, 655-688, doi:10.1146/ annurev.earth.34.031405.125144.

Seager, R., N. Naik, and G. A. Vecchi, 2010: Thermodynamic and dynamic mechanisms for large-scale changes in the hydrological cycle in response to global warming. J. Climate, 23, 4651-4668, doi:10.1175/2010JCLI3655.1.

—, H. Liu, N. Henderson, I. Simpson, C. Kelley, T. Shaw, Y. Kushnir, and M. Ting, 2014a: Causes of increasing aridification of the Mediterranean region in response to rising greenhouse gases. J. Climate, doi:10.1175/JCLI-D-13-00446.1, in press.

Shaw, T. A., 2014: On the role of planetary-scale waves in the abrupt seasonal transition of the Northern Hemisphere general circulation. J. Atmos. Sci., 71, 1724-1746, doi:10.1175/ JAS-D-13-0137.1. 
Simpson, I. R., M. Blackburn, and J. D. Haigh, 2009: The role of eddies in driving the tropospheric response to stratospheric heating perturbations. J. Atmos. Sci., 66, 1347-1365, doi:10.1175/2008JAS2758.1.

Solomon, S., D. Qin, M. Manning, M. Marquis, K. Averyt, M. M. B. Tignor, H. L. Miller Jr., and Z. Chen, Eds., 2007: Climate Change 2007: The Physical Science Basis. Cambridge University Press, 996 pp.

Stephenson, D. B., and I. M. Held, 1993: GCM response of northern winter stationary waves and storm tracks to increasing amounts of carbon dioxide. J. Climate, 6, 1859-1870, doi:10.1175/1520-0442(1993)006<1859:GRONWS>2.0.CO;2.

Swart, N. C., and J. C. Fyfe, 2012: Observed and simulated changes in the Southern Hemisphere surface westerly wind-stress. Geophys. Res. Lett., 39, L16711, doi:10.1029/2012GL052810.

Wallace, J. M., and M. L. Blackmon, 1983: Observations of lowfrequency atmospheric variability. Large-Scale Dynamical Processes in the Atmosphere, B. Hoskins, Ed., Academic Press, 55-91.

Wang, L., and P. J. Kushner, 2011: Diagnosing the stratospheretroposphere stationary wave response to climate change in a general circulation model. Geophys. Res. Lett., 116, D16113, doi:10.1029/2010JD015473.
Wilcox, L. J., A. J. Charlton-Perez, and L. J. Gray, 2012: Trends in Austral jet position in ensembles of high- and low-top CMIP models. J. Geophys. Res., 117, D13115, doi:10.1029/ 2012JD017597.

Woollings, T., 2010: Dynamical influences on European climate: An uncertain future. Philos. Trans. Roy. Soc. London, 368, 3733-3756, doi:10.1098/rsta.2010.0040.

_ and M. Blackburn, 2012: The North Atlantic jet stream under climate change and its relation to the NAO and EA patterns. J. Climate, 25, 886-902, doi:10.1175/JCLI-D-11-00087.1.

Wu, Y., R. Seager, M. Ting, N. Naik, and T. A. Shaw, 2012: Atmospheric circulation response to an instantaneous doubling of carbon dioxide. Part I: Model experiments and transient thermal response in the troposphere. J. Climate, 25, 28622879, doi:10.1175/JCLI-D-11-00284.1.

, T. A. Shaw, M. Ting, and N. Naik, 2013: Atmospheric circulation response to an instantaneous doubling of carbon dioxide. Part II: Atmospheric transient adjustment and its dynamics. J. Climate, 26, 918-935, doi:10.1175/ JCLI-D-12-00104.1.

Yin, J. H., 2005: A consistent poleward shift of the storm tracks in simulations of 21 st century climate. Geophys. Res. Lett., 32, L18701, doi:10.1029/2005GL023684. 